\title{
Myristoylated alanine-rich C-kinase substrate effector domain phosphorylation regulates the growth and radiation sensitization of glioblastoma
}

\author{
NICHOLAS J. EUSTACE ${ }^{1}$, JOSHUA C. ANDERSON ${ }^{1}$, CATHERINE P. LANGFORD ${ }^{2}$, HOA Q. TRUMMELL ${ }^{1}$, \\ PATRICIA H. HICKS ${ }^{1}$, JOHN S. JARBOE ${ }^{3}$, JAMES A. MOBLEY ${ }^{4}$, ANITA B. HJELMELAND ${ }^{5}$, \\ JAMES R. HACKNEY ${ }^{6}$, RUNE T. PEDERSEN ${ }^{7}$, KADIA COSBY $^{1}$, G. YANCEY GILLESPIE ${ }^{2}$, \\ JAMES A. BONNER ${ }^{1}$ and CHRISTOPHER D. WILLEY ${ }^{1}$
}

\begin{abstract}
Departments of ${ }^{1}$ Radiation Oncology, and ${ }^{2}$ Neurosurgery, University of Alabama at Birmingham, Birmingham, AL 35294;
${ }^{3}$ Department of Radiation Oncology, University of Miami Miller School of Medicine, Miami, FL 33136;

Departments of ${ }^{4}$ Surgery, ${ }^{5}$ Cell molecular and Developmental Biology, and ${ }^{6}$ Pathology,

University of Alabama at Birmingham, Birmingham, AL 35294, USA; ${ }^{7}$ ChemoMetec, DK-3450 Allerod, Denmark
\end{abstract}

Received October 19, 2018; Accepted March 6, 2019

DOI: 10.3892/ijo.2019.4766

\begin{abstract}
Glioblastoma harbors frequent alterations in receptor tyrosine kinases, phosphatidylinositol-3 kinase (PI3K) and phosphatase and tensin homolog (PTEN) that dysregulate phospholipid signaling driven tumor proliferation and therapeutic resistance. Myristoylated alanine-rich C-kinase substrate (MARCKS) is a $32 \mathrm{kDa}$ intrinsically unstructured protein containing a polybasic (+13) effector domain (ED), which regulates its electrostatic sequestration of phospholipid phosphatidylinositol (4,5)-bisphosphate (PIP2), and its binding to phosphatidylserine, calcium/calmodulin, filamentous actin, while also serving as a nuclear localization sequence. MARCKS ED is phosphorylated by protein kinase C (PKC) and Rho-associated protein kinase (ROCK) kinases; however, the impact of MARCKS on glioblastoma growth and radiation sensitivity remains undetermined. In the present study, using a tetracycline-inducible system in PTEN-null U87 cells, we demonstrate that MARCKS overexpression suppresses growth and enhances radiation sensitivity in vivo. A new image cytometer, Xcyto10, was utilized to quantify differences in MARCKS ED phosphorylation on localization and its association with filamentous actin. The overexpression of the non-phosphorylatable ED mutant exerted growth-suppressive and radiation-sensitizing effects, while the pseudo-phosphorylated ED mutant exhibited an enhanced colony formation and clonogenic survival ability. The identification of MARCKS
\end{abstract}

Correspondence to: Dr Christopher D. Willey, Department of Radiation Oncology, University of Alabama at Birmingham, HSROC 2232C, 619 19th Street South, Birmingham, AL 35249, USA E-mail: cwilley@uabmc.edu

Key words: myristoylated alanine-rich C-kinase substrate effector domain, glioblastoma, growth inhibition, growth promotion, radiation sensitivity protein-protein interactions using co-immunoprecipitation coupled with tandem mass spectrometry revealed novel MARCKS-associated proteins, including importin- $\beta$ and ku70. On the whole, the findings of this study suggest that the determination of the MARCKS ED phosphorylation status is essential to understanding the impact of MARCKS on cancer progression.

\section{Introduction}

Glioblastoma (GBM) is the most common primary adult brain tumor, and it continues to have a dismal median survival of 15 months despite maximal safe surgical resection with radiotherapy and chemotherapy (1-3). A deeper understanding of the mechanisms driving the aggressiveness of and high levels of therapeutic resistance in GBM is needed in order to develop novel effective therapies. GBM is well characterized as a pathway-driven disease $(4,5)$ with alterations in receptor tyrosine kinases (RTKs), activating mutations in PI3CA (p110) and PIK3R1 (p85) or the loss of phosphatase and tensin homolog (PTEN) occurring in up to $88 \%$ of GBM cases (6), which promotes the conversion of phosphatidylinositol $(4,5)$-bisphosphate [Ptdlns $(4,5) \mathrm{P}_{2}$ ] into phosphatidylinositol $(3,4,5)$-trisphosphate $\left[\operatorname{Ptdlns}(3,4,5) \mathrm{P}_{3}\right]$. The accumulation of $\operatorname{Ptdlns}(3,4,5) \mathrm{P}_{3}$ promotes the localization of proteins containing pleckstrin homology (PH) domains to the plasma membrane, enhancing downstream signaling, such as the activation of AKT and mammalian target of rapamycin complex (mTORC), promoting cancer growth and therapeutic resistance (7), as well as oncogenic transformation (8). Ptdlns $(4,5) \mathrm{P}_{2}$ has important functions in cell migration (9) and calcium regulation (10).

Myristoylated alanine-rich C-kinase substrate (MARCKS) is an intrinsically unstructured protein highly expressed in the brain that was originally thought to be an $80 \mathrm{kDa}$ protein by SDS gel electrophoresis due to its unique amino acid composition (11), but later shown to be $31.75 \mathrm{kDa}$ by cDNA sequencing and mass spectrometry (10-15). The MARCKS effector domain (ED) is 
known to electrostatically sequester $\operatorname{Ptd} \operatorname{lns}(4,5) \mathrm{P}_{2}$ at the plasma membrane, blocking its cleavage by phospholipase C (PLC) or phosphorylation by phosphatidylinositide 3-kinase (PI3K) $(13,16)$ and crosslink filamentous actin (F-actin) $(10,14,17,18)$. The ability of MARCKS to sequester Ptdlns $(4,5) \mathrm{P}_{2}$, renders it potentially as a potent tumor suppressor when membrane-bound due to the frequency of PI3K hyperactivation and the loss of PTEN in GBM. MARCKS has two domains that promote plasma membrane binding, an N-terminal myristoylation moiety and an electrostatically charged ED. Myristoylation alone has been shown to be insufficient for membrane binding, instead, requiring contributions from its cationic ED (13). MARCKS membrane binding is electrostatically maintained through the attraction of the positively charged lysine residues of the ED (+13) to negatively charged phospholipid head groups, such as Ptdlns(4,5) $\mathrm{P}_{2}(19)$, and by the embedding of phenylalanine residues of the ED into the acyl chain regions of the phospholipids in the membrane (20). MARCKS plasma membrane and actin binding are regulated through two major mechanisms: i) The phosphorylation of up to four serine residues in the ED by PKC (21) or ROCK kinases (22); and ii) the binding of the ED by calcium $\left(\mathrm{Ca}^{2+}\right)$ /calmodulin $(\mathrm{CaM})(16,17)$. These events, however, are mutually exclusive, allowing competitive interactions to occur at MARCKS ED, enabling 'crosstalk' across distinct signaling pathways (13). MARCKS crosslinking of F-actin at the plasma membrane is lost either with ED phosphorylation or $\mathrm{Ca}^{2+} / \mathrm{CaM}$ binding $(14,17,18)$. In addition to Ptdlns $(4,5) \mathrm{P}_{2}$ sequestration and F-actin crosslinking, MARCKS ED binds phosphatidylserine (PS) $(23,24)$, and functions as a nuclear localization sequence (NLS) (25). In cancer, MARCKS expression has been associated with both tumor-suppressing and tumor-promoting phenotypes (26-29); however, its inconsistent role in cancer progression has been attributed to a lack of information on ED phosphorylation status until more recent studies (10,14,30-32). In GBM, Micallef et al previously demonstrated that the epidermal growth factor receptor variant III (EGFR-VIII) invasive phenotype was driven in part by the phosphorylation of MARCKS ED (32). Additionally, Jarboe et al demonstrated that the knockdown of MARCKS in GBM promoted cell proliferation and radiation resistance through upregulations in non-homologous end joining (NHEJ) DNA repair mechanisms, and that patients with a high MARCKS expression, particularly in MGMT unmethylated GBM tumors, had substantial survival benefits (33). Since MARCKS itself is not mutated in GBM (34), it is suggested that primarily epigenetic, post-transcriptional or post-translational modifications will overcome the MARCKS tumor-suppressing effects.

In this study, we further examine the hypothesis that MARCKS functions as a tumor suppressor in GBM, by overexpressing MARCKS and investigating its effects on growth suppression and radiation sensitivity. We hypothesized that the unphosphorylated ED would have growth-suppressing and radiation-sensitizing effects, while ED phosphorylation would block these tumor-suppressing effects.

\section{Materials and methods}

Cells and cell culture. U87 and U373 glioblastoma lines were originally acquired from the University of Uppsala
(Uppsala, Sweden), and 293FT cells were acquired from ATCC (Manassas, VA, USA). All cell lines were cultured as previously described in Dulbecco's modified Eagle's medium with $10 \%$ fetal bovine serum and $1 \%$ penicillin-streptomycin at $37^{\circ} \mathrm{C}$ and $5 \% \mathrm{CO}_{2}$ (33). All tetracycline inductions were accomplished at $2 \mu \mathrm{g} / \mathrm{ml}$ doxycycline in complete DMEM.

MARCKS plasmid production. U87 cells were engineered to overexpress MARCKS or the MARCKS ED mutants in a tetracycline-dependent manner as previously described (25). Other ED mutants were similarly constructed. Concisely, the ViraPower HiPerform T-REx Gateway Expression System (cat. no. A11141) and the pENTR221 entry vector containing the wild-type (WT) sequence was purchased from Thermo Fisher Scientific (Waltham, MA, USA). The pENTR221-MARCKS vector was cloned into the pLenti6.3/TO/V5-DEST destination vector. Mutant MARCKS ED constructs were synthesized by and cloned into the pUC57 vector by GenScript (Piscataway, NJ, USA). Fragments from these plasmids with the mutations were cloned into the pLenti6.3/TO/V5-MARCKS-WT using restriction sites and standard protocols to generate MARCKS mutant lentiviral plasmids containing blasticidin resistance and a V-5 epitope tag. An empty vector control plasmid (CTL) was also generated.

Lentiviral particle production. Lentiviral particles were produced as previously described (33). Concisely, lentivirus was generated by co-transfection of $293 \mathrm{FT}$ cells with an appropriate amount of MARCKS pLenti6.3/TO/V5 plasmid, pCMV-VSV-G envelope plasmid (Addgene plasmid 8454) and psPAX2 packaging plasmid (Addgene plasmid 12260) (both from Addgene, Watertown, MA, USA) with Lipofectamine 2000 (cat. no. 11668) in Opti-MEM (cat. no. 11058) (both from Thermo Fisher Scientific). The medium was changed the following morning, and enriched viral medium was collected $24 \mathrm{~h}$ later, filtered through a $0.45-\mu \mathrm{m}$ filter, aliquoted and stored at $-80^{\circ} \mathrm{C}$. Lentivirus was quantified using QuickTiter p24 ELISA (Cell Biolabs, Inc., San Diego, CA, USA).

Stable cell line selection and validation. U87 cells were first transduced with p24 quantified tetracycline-repressor (Tet-R) packaged lentiviral particles along with $8 \mu \mathrm{g} / \mathrm{ml}$ polybrene as previously described (25). A total of $500 \mu \mathrm{g} / \mathrm{ml} \mathrm{Geneticin} \mathrm{(G418;}$ Life Technologies/Thermo Fisher Scientific) was used to select for Tet-R-positive cells. Tet-R-positive cells were subsequently transduced with similar amounts of p24 quantified CTL, WT+, NP, PP or $\Delta$ ED lentiviral particles. Subsequently, $1 \mu \mathrm{g} / \mathrm{ml}$ blasticidin was used to select successfully transduced cells. Robust tetracycline-dependent MARCKS expression was validated by western blot analysis following a 72-h induction with $2 \mu \mathrm{g} / \mathrm{ml}$ of doxycycline (Life Technologies/Thermo Fisher Scientific) or the phosphate-buffered saline vehicle control. MARCKS mutations were additionally validated by PCR amplification using CMV forward primer (5'-CGCAAATGGGCGGTAGGCGTG-3') and V5 reverse primer (5'-ACCGAGGAGAGGGTTAGGGAT-3') coupled and sequenced using Sanger sequencing of an internal MARCKS forward primer (5'-GAACGGACAGGAGGATGG-3') and V5 reverse primer (5'-ACCGAGGAGAGGGTTAGGGAT-3'). 
Western blot analysis and antibodies. Western blot analysis was performed as previously described (35). Briefly, chilled mammalian protein extraction reagent (MPER) lysis buffer (cat. no. 78501; Pierce/Thermo Fisher Scientific, Rockford, IL, USA) was supplemented with protease (\#P8340) and phosphatase inhibitors (P0044 and P5726) (both from Sigma-Aldrich, St. Louis, MO, USA) before lysing the cells for $30 \mathrm{~min}$ on ice. The samples were subsequently centrifuged at $12,000 \times \mathrm{g}$ for $10 \mathrm{~min}$ at $4^{\circ} \mathrm{C}$, and the supernatant was collected and quantified using the Pierce BCA protein assay kit. Samples were separated by electrophoresis through a $10 \%$ SDS-polyacrylamide gel (SDS-PAGE) and transferred onto a PVDF membrane (Immobilon, Emdmilipore, Burlington, MA, USA). The blots were blocked in 5\% BSA for $1 \mathrm{~h}$ and probed with the following antibodies at $4{ }^{\circ} \mathrm{C}$ overnight with gentle rocking using manufacturer recommended dilutions: V5-HRP (P/N 46-0708; Invitrogen/Thermo Fisher Scientific), MARCKS anti-rabbit (ab52616), MARCKS anti-mouse (ab55451) (both from Abcam, Cambridge, MA, USA), phosphorylated (p-)histone H2AX S139 (9718S), p-Akt (Ser473; D9E; \#4060), p-Akt (Thr308; C31E5E; \#2965), Akt (C67E7; \#4691), PKCa (\#2056) (all from Cell Signaling Technology, Danvers, MA, USA), rabbit IgG control (20304E; Imgenex/Novus Biologicals, Centennial, CO, USA) and Actin (sc-1616-R), lamin A/C (sc-7292), $\alpha$-tubulin (sc-53646) (all from Santa Cruz Biotechnology, Santa Cruz, CA, USA). The blots were treated with secondary HRP antibody at 1:5,000 for $1 \mathrm{~h}$ at room temperature with gentle rocking, and detected with enhanced chemiluminescence (ECL) using Western Lighting-Plus ECL substrate (PerkinElmer, Inc., Waltham, MA, USA) and blue X-ray film. Densitometry was performed using ImageJ software with 8-bit images and normalized to the loading control.

Isolation of nuclear and cytoplasmic fractionations. Plate and doxycycline induce for $72 \mathrm{~h}$ a sufficient number of cells to have approximately 10 million cells in a pellet following collection. The modified nuclear extraction protocol (\#40410; Active Motif, Carlsbad, CA, USA) was as follows: The cells were collected by removing the media and washing with $1 \mathrm{X}$ ice-cold PBS. This was followed by the addition of $1.5 \mathrm{ml}$ cold PBS and $1 \mathrm{ml}$ trypsin per plate until the cells lifted. The cells were then transferred to a $15 \mathrm{ml}$ centrifuge tube and spun for $5 \mathrm{~min}$ at $400 \mathrm{x}$ g at $4^{\circ} \mathrm{C}$. The supernatant discarded, and the cells were then rinsed once more with $2 \mathrm{ml}$ ice-cold PBS and spun for $5 \mathrm{~min}$ at $400 \mathrm{x} \mathrm{g}$ at $4^{\circ} \mathrm{C}$ and the supernatant was removed. The pellet was resuspended in $1 \mathrm{ml}$ of ice-cold $1 \mathrm{X}$ hypotonic buffer, with gentle pipetting up and down and transferring to a chilled $1.5 \mathrm{ml}$ micro-centrifuge tube and incubation on ice for $30 \mathrm{~min}$. Subsequently, $50 \mu \mathrm{l}$ detergent was added and the mixture was vortexed for $10 \mathrm{sec}$ at the highest setting, and then spun for $2 \mathrm{~min}$ at $14,000 \mathrm{x} \mathrm{g}$ at $4^{\circ} \mathrm{C}$. The supernatant was then transferred (cytoplasmic fraction) into a new chilled micro-centrifuge tube and frozen at $-20^{\circ} \mathrm{C}$ for western blot analysis. The remaining fluid was aspirated until only the pellet remained. The pellet was then rinsed with $1 \mathrm{ml} 1 \mathrm{X}$ PBS and spun down for $2 \mathrm{~min}$ at $14,000 \mathrm{x} \mathrm{g}$ at $4^{\circ} \mathrm{C}$ to aspirate off the supernatant. Nuclear extraction was continued using $50 \mu \mathrm{l}$ of complete MPER lysis buffer supplemented with protease (\#P8340) and phosphatase inhibitors (P0044 and P5726) (both from Sigma-Aldrich) for $30 \mathrm{~min}$ on ice. The mixture was then spun for $2 \mathrm{~min}$ at $14,000 \mathrm{xg}$ at $4^{\circ} \mathrm{C}$, and the supernatant was collected and frozen at $-20^{\circ} \mathrm{C}$ for western blot analysis (nuclear fraction). Protein determination and probing was performed for western blot analysis using the above-mentioned protocol.

Cell proliferation assay. A total of 5,000 cells per well $(n=12)$ were counted using a hemocytometer and plated for each of the validated MARCKS mutant lines into black 96-well plates containing $100 \mu \mathrm{l}$ of DMEM with $10 \%$ FBS and $2 \mu \mathrm{g} / \mathrm{ml}$ of the doxycycline (doxycycline medium). The U87 ATP levels were measured using a PerkinElmer ATPlite Luminescence Assay System (PerkinElmer, Waltham, MA, USA) as per the manufacturer's instructions at 5-7 days after plating. U373 cell viability was determined using same plating conditions $(5,000$ cells/well $100 \mu \mathrm{l})$, however, using a CellTiter Glo (Promega, Madison, WI, USA) kit as per the manufacturer's protocol $(n=4)$. Luminescence was determined on a BioTek H1 Hybrid Synergy (BioTek, Winooski, VT, USA).

Colony formation and clonogenic survival assay. The clonogenic assay was performed as previously described (33). In brief, one-step clonogenic fixation and staining solution were made by combining $750 \mathrm{ml}$ of deionized water with $250 \mathrm{ml}$ of 25\% glutaraldehyde (G6257-1L; Sigma-Aldrich) and $5 \mathrm{~g}$ of crystal violet (C581-100; Thermo Fisher Scientific) in a 1 liter bottle and mixing at room temperature until the mixture was dissolved. Cells were then doxycycline-induced for $72 \mathrm{~h}$ before counting using a hemocytometer and diluting to a defined concentration. Pre-determined cell numbers were plated in 60-mm dishes with a $4 \mathrm{ml}$ total volume and allowed to attach overnight before irradiating in a single fraction at indicated doses for clonogenic assay (colony formation assay does not receive irradiation). Fourteen days after plating, cells were fixed and stained with the clonogenic staining solution for $30 \mathrm{~min}$ at room temperature, before gently rinsing plates with cold tap water and drying upside-down overnight. Colonies were counted at $\mathrm{x} 45$ magnification using a dissecting microscope (Stereomaster/Thermo Fisher Scientific, Pittsburgh, PA, USA) and were determined in the presence of $>50$ cells. The surviving fraction (SF) was calculated by using the following equation: (number of colonies formed/number of cells plated)/(number of colonies from the sham-irradiated group/number of cells plated). Results are plotted in a semi-logarithmic format using GraphPad Prism 7.04 and standard error of the mean (SEM) error bars. Dose enhancement ratio=(dose $(\mathrm{Gy})$ for control (CTL)/dose for ED mutant) at $\mathrm{SF}=0.2$.

Immunofluorescence staining, and quantification of fluorescence intensity and localization on the image cytometer Xcyto10. In total, 50,000 cells were plated in a 24-well plate containing $12 \mathrm{~mm}$ poly-D-Lysine coated round coverslips and $500 \mu \mathrm{l}$ doxycycline-containing medium. Cells were induced for $72 \mathrm{~h}$ before the medium was removed. The cells were then rinsed with $1 \mathrm{ml}$ room temperature PBS and fixed with $500 \mu \mathrm{l}$ of $4 \%$ paraformaldehyde for $12 \mathrm{~min}$ at room temperature. The cells were then permeabilized with $0.1 \%$ Triton X-100 PBS for $20 \mathrm{~min}$ and blocked in 5\% BSA, 1\% goat serum PBS for $40 \mathrm{~min}$ at room temperature. Subsequently, $250 \mu \mathrm{l}$ of 1:250 primary antibody in $0.5 \%$ BSA was added per coverslip and incubated overnight at $4^{\circ} \mathrm{C}$. Coverslips were rinsed 3 times 
for 5 min with $500 \mu$ l PBS before a 2-h room temperature incubation in the dark with 1:1,000 AlexaFluor 546 anti-rabbit IgG secondary antibody (A11010) and $1 \mathrm{X}$ phalloidin-FITC (F432) (both from Invitrogen/Thermo Fisher Scientific) dye in $0.5 \%$ BSA PBS. The cells were then rinsed with $500 \mu 1$ PBS 3 times for 5 min before co-staining with 1:1,000 BlueMask-1 (ChemoMetec, Allerod, Denmark) and 1:250 DAPI $(2 \mu \mathrm{g} / \mathrm{ml})$ at for $30 \mathrm{~min}$ at room temperature. Coverslips were rinsed in $500 \mu \mathrm{l} 1 \mathrm{X}$ PBS for $5 \mathrm{~min}$ before mounting on Xcyto 2-Sample slides (ChemoMetec) with ProLong Glass Antifade mountant with DAPI (Thermo Fisher Scientific) overnight in the dark. Slides were analyzed on the image cytometer Xcyto10 (ChemoMetec) at x20 magnification with excitation/filter sets AF546 (LED535; 582-636), AF488 (LED488; 513-555), MASK (LED405; 430-475) DAPI (LED405; 573-613) for high-resolution images and the quantification of fluorescent intensities and localization. Similarity scores were calculated using XcytoView (ChemoMetec) and represent the log-transformed Pearson's correlation coefficients between two channels. Similarity scores between MARCKS and DNA were used to determine MARCKS relative nuclear localization, and similarity scores between MARCKS and phalloidin were used to compare MARCKS and F-actin association.

Quantification of $\gamma H 2 A X$ fociformation. Cells were adhered to $12 \mathrm{~mm}$ poly-D-Lysine-coated round coverslips (REF354086; Corning, Inc., Corning, NY, USA) in $500 \mu 1$ medium containing doxycycline for $72 \mathrm{~h}$ prior to $8 \mathrm{~Gy}$ irradiation or $0 \mathrm{~Gy}$ (Sham). Cells were fixed at indicated time-points with ice-cold methanol for $12 \mathrm{~min}$ at $-20^{\circ} \mathrm{C}$ and blocking with $5 \%$ BSA $1 \%$ goat serum for 40 min. 1:400 Histone H2AX S139 (9718S; Cell Signaling Technology) primary and 1:1,000 AlexaFluor 488 (ab150077; Abcam) secondary antibodies were used to stain for $\gamma \mathrm{H} 2 \mathrm{AX}$ and coverslips were subsequently stained with DAPI and BlueMask-1. Coverslips were mounted slides using with ProLong diamond anti-fade mountant. Cells were imaged on EVOS FL (Thermo Fisher Scientific) microscope at x20 magnification, with 4 images per time-point collected and were scored by blinded observers. Positive events were defined as $\geq 10$ foci per cell, and the percentage of positive cells per field was graphed using Prism software. The mean nuclear intensity of U373 was acquired using Xcyto10 at a 20X resolution with fluorescent intensities measured using XcytoView. The graph and statistics were generated using GraphPad 7.04 software with error bars in SEM and Log-rank (Mantel-cox) test used to generate the P-values.

Equipment and settings. The images shown in Figs. 1, S1 and S2 were acquired using a Xcyto10 Image cytometer with a 20X objective lenses on 2 sample slides as follows: Fig. 1 and S1: MARCKS-AF546 (400 msec, LED535; 582-636), phalloidin-AF488 (400 msec, LED488; 513-555), DAPI (400 msec, LED405; 573-613); Fig. S2: MARCKS-AF546 (800 msec, LED535; 582-636), phalloidin-AF488 (800 msec, LED488; 513-555), DAPI (400 msec, LED405; 573-613). Images were acquired from XcytoView screen captures using linear scale display properties as follows: Figs. 1 and S1: TMARCKS (Min 142, Max 2207), phalloidin (Min 1874, Max 89459); DAPI (Min 1142 Max 16188)]; Fig. S2: TMARCKS (Min 44, Max 5441), phalloidin (Min 868, Max 84947); DAPI (Min 1987
Max 1524)]. The colony formation images shown in Fig. 3C were acquired using a $12 \mathrm{MP}$ camera (Iphone7), and the colony images shown in Fig. 3D were acquired under a dissecting microscope (x45 magnification) using a $12 \mathrm{MP}$ camera (iPhone X). Blots were acquired on an Epson Perfection scanner.

Comet assay. A total of 100,000 cells were plated in 60-mm dishes and induced with doxycycline for $72 \mathrm{~h}$. At $24 \mathrm{~h}$ prior to the assay, the medium was exchanged for fresh doxycycline-containing media to remove any floating cells. Cells were irradiated with 16 Gy and collected at the following time-points [immediately post-irradiation (T0), $30 \mathrm{~min}, 1 \mathrm{~h}$ and $4 \mathrm{~h}$ ] by gently lifting them off the plate into the medium using a rubber policeman. T0 cells were irradiated on ice and scraped immediately following irradiation. The Trevigen Comet assay (Trevigen, Gaithersburg, MD, USA) was used under neutral conditions and manufacturer-provided materials and protocol. Tail moments from 200 cells per spot (3X replicates) were determined using a Zeiss AX10 observer A1 microscope and Comet Assay IV version 4.3 software. The graph was generated using tail moment values in GraphPad 7.04 software.

Immunoprecipitation coupled with mass spectrometry. U87 WT+ cells were cultured to $90 \%$ confluence in a $75 \mathrm{~cm}^{2}$ flask with standard doxycycline medium for $72 \mathrm{~h}$, prior to trypsin disassociation, rinsing with PBS and flash-freezing in liquid nitrogen. The cells were later lysed in chilled MPER lysis buffer supplemented with protease (\#P8340) and phosphatase inhibitors (P0044 and P5726) (both from Sigma-Aldrich) for $30 \mathrm{~min}$ on ice. The lysate was centrifuged at $12,000 \mathrm{x} \mathrm{g}$ for $10 \mathrm{~min}$ at $4^{\circ} \mathrm{C}$ and protein was quantified by BCA assay. Catch and Release version 2.0 (EMD Millipore, Temecula, CA, USA) was used for immunoprecipitation with the following modifications to the manufacturer's protocol. $500 \mu \mathrm{g}$ protein was loaded into a $1.5 \mathrm{ml}$ centrifuge tube, along with a 1:200 dilution of MARCKS antibody (cat. no. 20661-1-AP; Proteintech, Rosemont, IL, USA) or normal rabbit IgG antibody (sc-2027; Santa Cruz Biotechnology). The lysate antibody mixture was rotated at $4^{\circ} \mathrm{C}$ for $15 \mathrm{~min}$. The lysate antibody mixture was then added to the spin column along with $10 \mu \mathrm{l}$ affinity ligand and $1 \mathrm{X}$ wash buffer for $500 \mu \mathrm{l}$ total volume. The spin column was rotated overnight at $4^{\circ} \mathrm{C}$ before proceeding with standard protocol eluting with $70 \mu \mathrm{l}$ of provided non-denaturing elution buffer. Flow through, washes and elutions were collected for evaluation by western blot analysis before submitting a sample to UAB mass spectrometry core for analysis. The sample was run on $10 \%$ Bis-tris gel and stained using the colloidal blue staining kit (LC60225; Thermo Fisher Scientific) following the manufacturer's protocol, with fixation for $10 \mathrm{~min}$ at room temperature using 50\% methanol, $10 \%$ acetic acid and staining for $12 \mathrm{~h}$ at room temperature. In total, 6 separate fractions were isolated using in-gel digestion with trypsin and analyzed using an nLC LTQ Velos Pro Orbitrap mass spectrometer (Thermo Fisher Scientific) for analysis. Scaffold 4.6.2 was used to compare identified proteins from mass spectrometry experiments and generate Venn diagram. GeneGo 4.9.18 was used to generate network and pathway maps of direct protein interactions from the 108 unique proteins identified in MARCKS immunoprecipitation experiments and not detected in IgG control. Link: https://portal.genego.com/ 
A

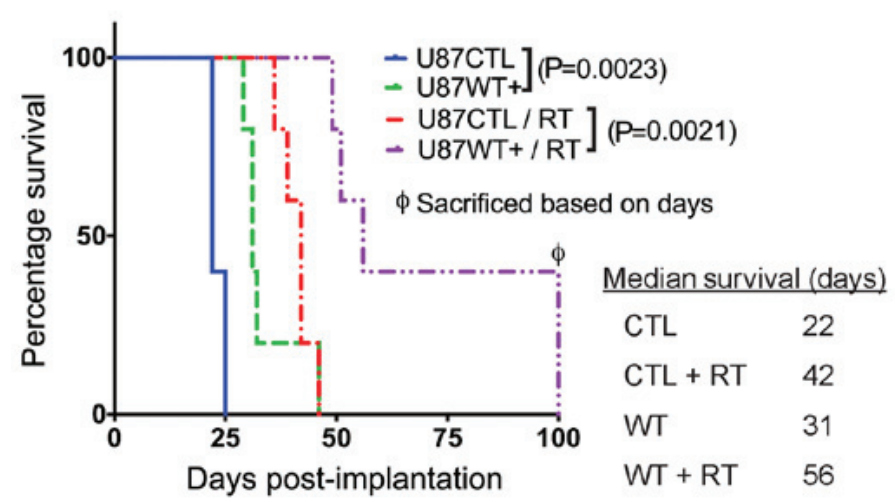

B
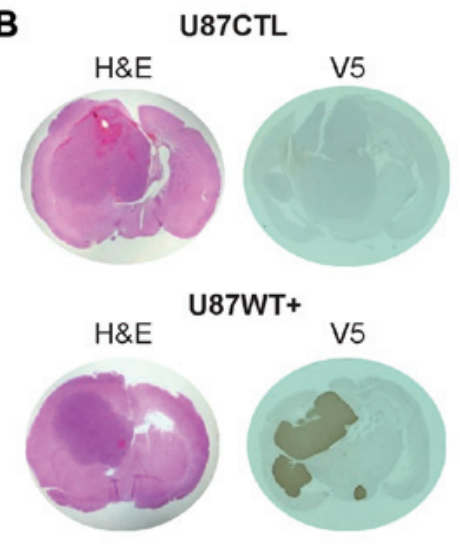

Figure 1. MARCKS overexpression prolongs survival and enhances radiation sensitivity in vivo. (A) U87 cells were orthotopically injected into the caudate putamen of five- to six-week-old athymic nude mice on doxycycline chow. Survival was determined at the first sign of neurologic symptoms. Mice that received RT mice received 12 Gy RT delivered in 2 Gy fractions 3 times a week $(\mathrm{n}=5)$. (B) Coronal slices of brains were collected at the day of sacrifice to verifying MARCKS induction by doxycycline diet via the presence of exogenous MARCKS V5 tag. P-values calculated using the Log-rank (Mantel-Cox) test. MARCKS, myristoylated alanine-rich C-kinase substrate; RT, radiotherapy. WT+, V5-tagged MARCKS vector; CTL, control.

Orthotopic implantation, cranial radiation and survival analysis. All animal studies were carried out in accordance with the policies set by the University of Alabama (UAB) Institutional Animal Care and Use Committee (IACUC) and performed according to their guidelines. Moreover, the experimental protocols were registered and approved by the UAB Occupational Health and Safety (Project no. 14-124). Five- to six-week-old female athymic nude mice (Charles River, Hartford, CT, USA) were started on doxycycline chow 1 week prior to an intracranial injection of 500,000 cells per mouse with the aid of UAB's Brain Tumor Animal Model Core. A total of 40 mice (20 for data shown in Fig. 1A and 20 for data shown in Fig. S3) were used with an average weight of 20-22 g per mouse. All mice were housed under the care and maintenance of UAB's fully accredited (AAALAC) animal resources program (ARP) with routine monitoring by veterinarians. Mice were housed no more than 6 to a cage and had 24-h access to food and water maintained daily. The animal room was maintained at $21^{\circ} \mathrm{C}$ and $50 \%$ humidity with 12-h light-dark cycles. Intracranial injections were carried out as previously described (36). In brief cells were suspended in a (1:1) mixture of methylcellulose and loaded into a $1 \mathrm{ml}$ Hamilton syringe with a 12-gauge needle. Mice were anesthetized using an intraperitoneal injection of ketamine $(100 \mathrm{mg} / \mathrm{kg})$ and xylazine $(15 \mathrm{mg} / \mathrm{kg})$, and a midline scalp incision was made and a burr hole was drilled $1 \mathrm{~mm}$ posterior to the coronal suture and $2 \mathrm{~mm}$ right of the midline. Subsequently, $5 \mu 1$ of cell mixture was stereotactically delivered to a depth of $2.5 \mathrm{~mm}$ into the right caudate-putamen of each mouse. The data shown in Fig. 1A are composed of 4 groups with 5 mice in each (2 with CTL, 2 with WT+) with 1 group of each cell type receiving either 12 Gy (6 by 2 Gy fractions) or sham irradiation (0 Gy). Mice were euthanized at the first appearance of neurological symptoms or at the request of veterinary staff using $\mathrm{CO}_{2}$ exposure at $20 \%$ chamber volume displacement/minute $(1.5 \mathrm{l} / \mathrm{min}$ in an IACUC approved chamber with a flow meter) for $\sim 5$ min followed by secondary cervical dislocation as per the AVMA guidelines. Brains were collected and halved through the injection site for preservation by both formalin and liquid nitrogen.
Statistical analysis and data reproducibility. All statistical analyses were calculated in Prism 8.0 (GraphPad) with P-values $<0.05$ considered to indicate statistically significant differences. Significance in Fig. 1 was calculated with the Log-rank (Mantel-Cox) test, and in Fig. 2, with the similarity score log-transformed Pearson's correlation. In Fig. 3, significance (A and B) was determined using one-way ANOVA with Dunnett's multiple comparison test, or (C) a two tailed t-test. In Fig. 4, significance was determined using two-way ANOVA with Dunnett's multiple comparison test. All experiments were repeated at least 2 times.

\section{Results}

MARCKS overexpression prolongs survival and enhances radiation sensitivity in GBM in vivo. We have previously shown that MARCKS protein expression is inversely associated with GBM proliferation and intracranial xenograft growth rates, with the knockdown of MARCKS in the PTEN-null line, $\mathrm{U} 251$, resulting in an enhanced radiation resistance (33). In this study, to establish whether MARCKS overexpression can inhibit GBM growth and enhance radiation sensitivity, we orthotopically implanted the PTEN-null U87 cell line featuring a tetracycline-inducible, V5-tagged MARCKS vector (WT+) (25) or an empty control vector (CTL) into athymic nude mice and assessed the effects on survival. The WT+ mice were found to have a median survival of 31 days without radiotherapy (RT) and a 56-day survival following RT at 12 Gy (25-day enhancement), whereas the CTL mice had a median survival of 22 days without RT and a 42-day median survival with RT (20-day enhancement) (Fig. 1A). MARCKS overexpression increased the survival of the mice compared with the CTL group by $40 \%$ (9 days), while the WT+ mice receiving RT had an additional 25\% (5 days) increase in survival compared with the CTL mice (Fig. 1A). The successful overexpression of MARCKS in vivo was verified in post-mortem tumors by immunohistochemical staining (Fig. 1B). These data support the hypothesis that the overexpression of MARCKS is capable of suppressing growth and enhancing radiation sensitivity in PTEN-null GBM. 
A

\begin{tabular}{l|l|l|l|l|} 
WT+ & N-MYR & MH2 & WT ED - KKKKKRFSFKKSFKLLGFSFKKNKK & C-TERM-V5 \\
NP & N-MYR & MH2 & NP ED - KKKKKRFAFKKAFKLAGFAFKKNKK & C-TERM-V5 \\
\hline PP N-MYR & MH2 & PP ED - KKKKKRFDFKKDFKLDGFDFKKNKK & C-TERM-V5 \\
\hline & NED N-MYR & MH2 & C-TERM-V5 \\
\cline { 2 - 5 } & N-TE &
\end{tabular}
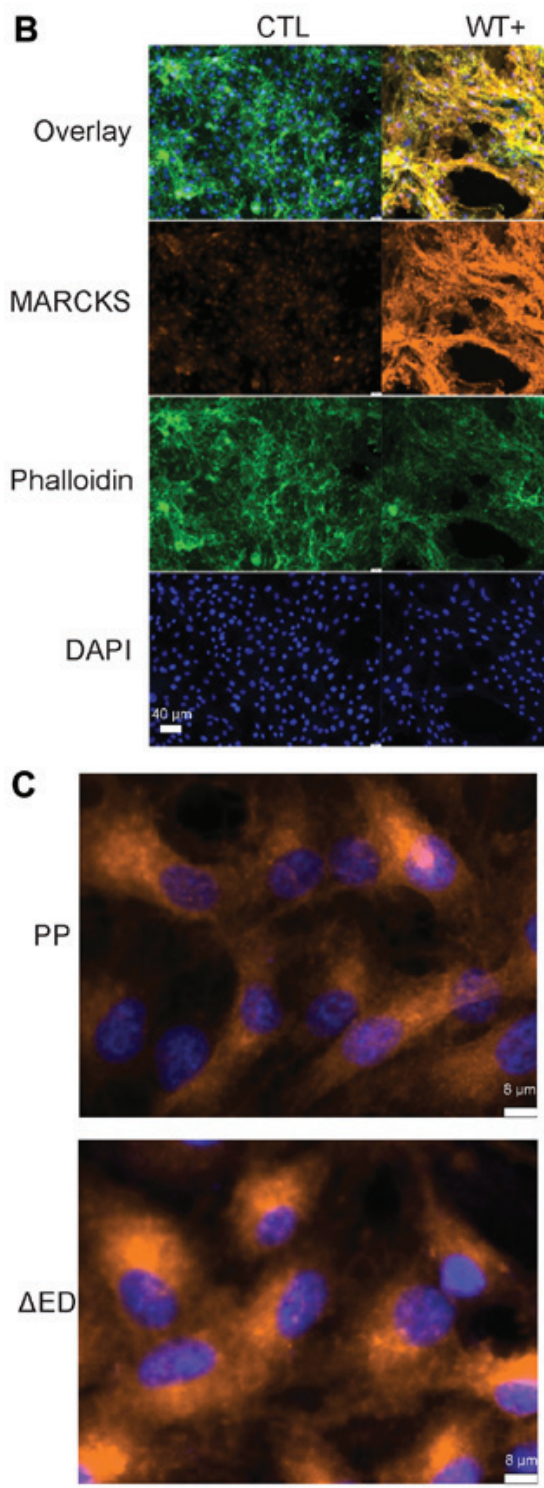

NP PP $\triangle \mathrm{ED}$
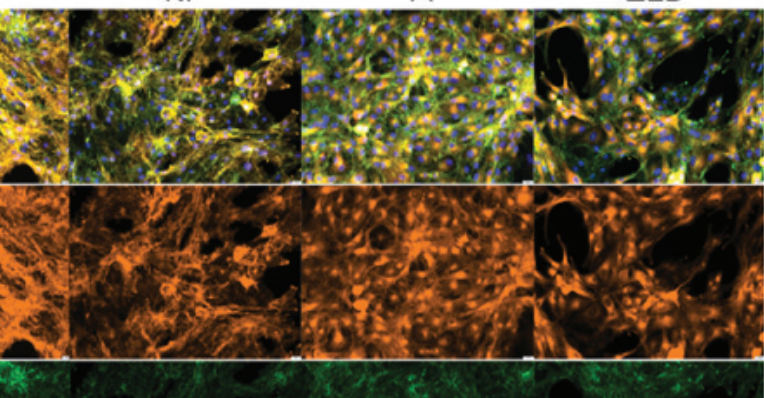
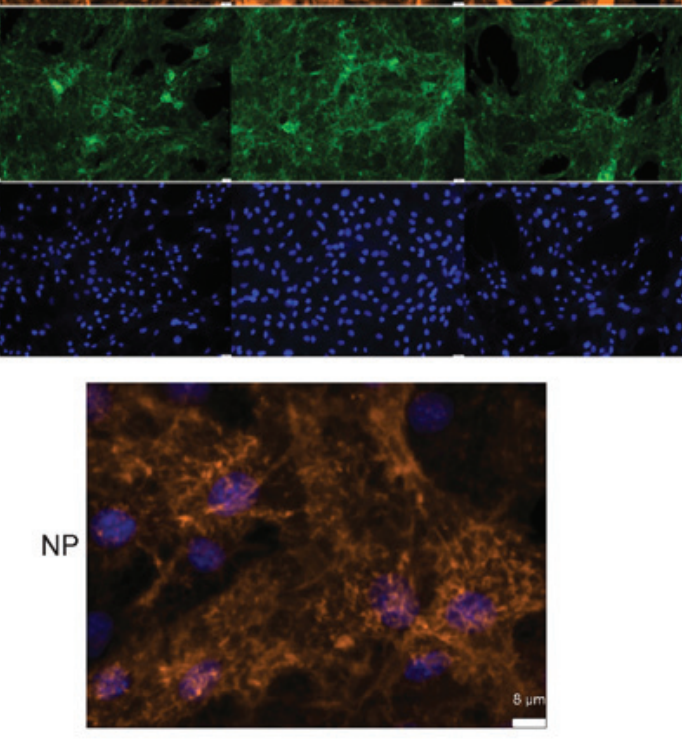

D

MARCKS \& actin Co-localization

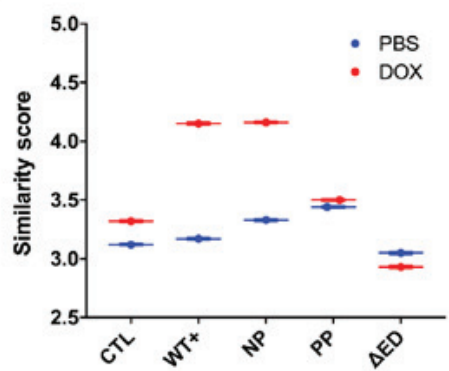

Figure 2. MARCKS ED phosphorylation regulates actin binding and the cellular localization of MARCKS in GBM. (A) Diagram of MARCKS effector domain mutants. WT+ has 4 PKC phosphorylatable serine residues in the effector domain. NP mutant replaces the 4 serine residues with alanine, PP replaces serines with aspartic acid residue and $\triangle \mathrm{ED}$ has a deleted effector domain. (B) Immunofluorescent imaging of U87 MARCKS effector domain mutants $72 \mathrm{~h}$ after doxycycline induction using the image cytometer Xcyto10 (x20 magnification). (C) Magnified view of MARCKS staining in NP, and PP mutants. Note the ruffled appearance of NP in contrast to the perinuclear staining of PP (x20 magnification, 400\% zoom). (D) Quantification of co-localization using similarity score to phalloidin (F-actin) calculated in XcytoView. The similarity score is calculated from the log-transformed Pearson's correlation between two separate fluorescent channels within the indicated compartment, graphed as mean \pm SEM. MARCKS, myristoylated alanine-rich C-kinase substrate; ED, effector domain; WT+, V5-tagged MARCKS vector; CTL, control; NP, non-phosphorylatable ED mutant; PP, pseudo-phosphorylated ED mutant; $\triangle E D$, deleted effector domain mutant.

MARCKS ED mutants mimic actin binding and the cellular localization of MARCKS phosphorylation in GBM. We then investigated the mechanisms through which the phosphorylation of the 4 serine residues present in MARCKS ED affect the ability of MARCKS to suppress GBM growth and radiation resistance by generating additional ED mutants: i) A non-phosphorylatable ED mutant (NP) replaced the serine residues with alanine, to prevent the loss of plasma membrane binding by phosphorylation; ii) a pseudo-phosphorylated ED mutant (PP) substituted the serine residues with aspartic acid, which prevented membrane binding by mimicking negatively charged phosphorylation groups; and iii) a deleted 
A

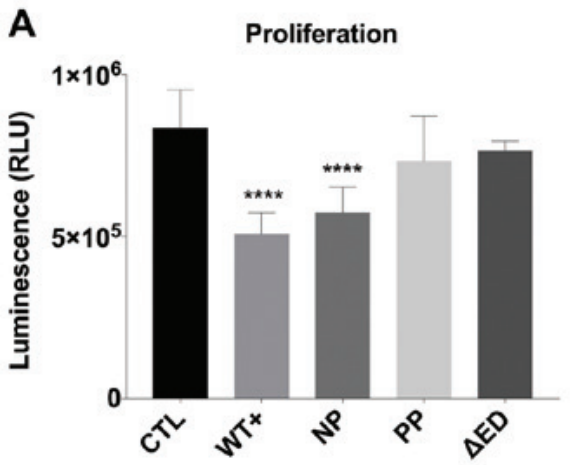

D

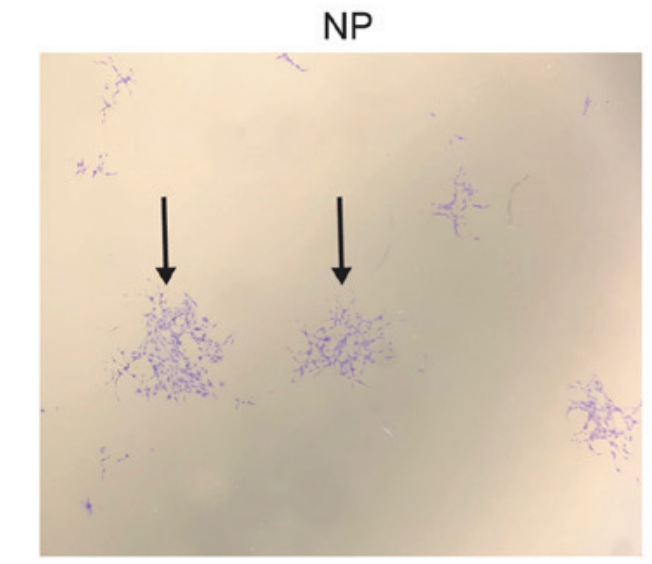

B

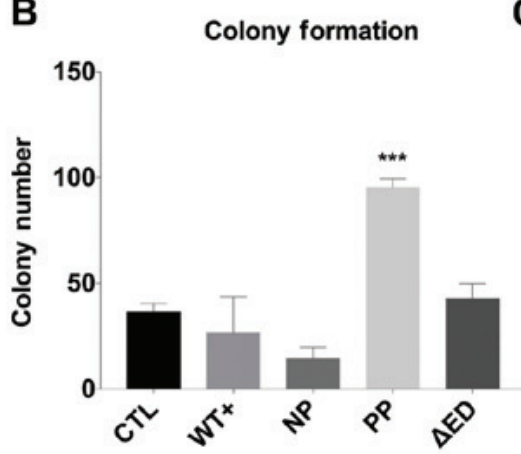

C

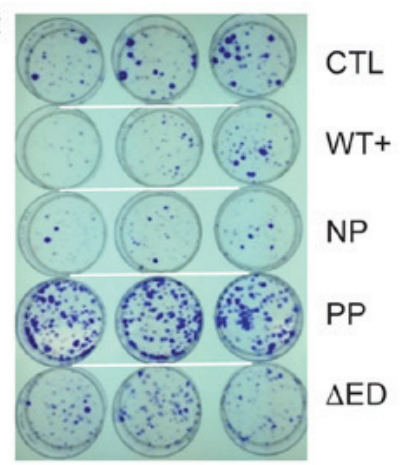

E

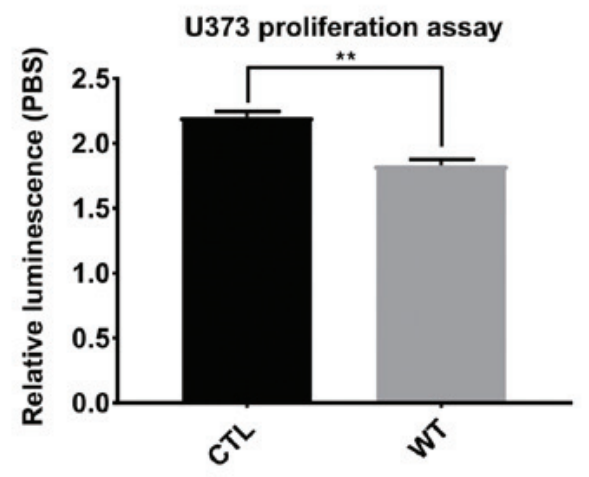

$\mathbf{F}$

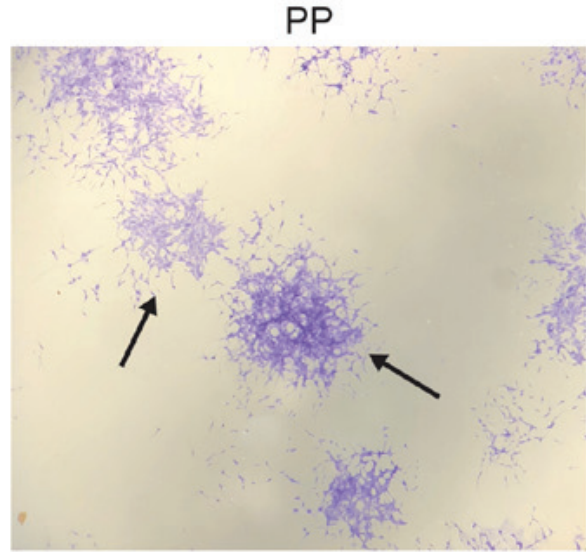

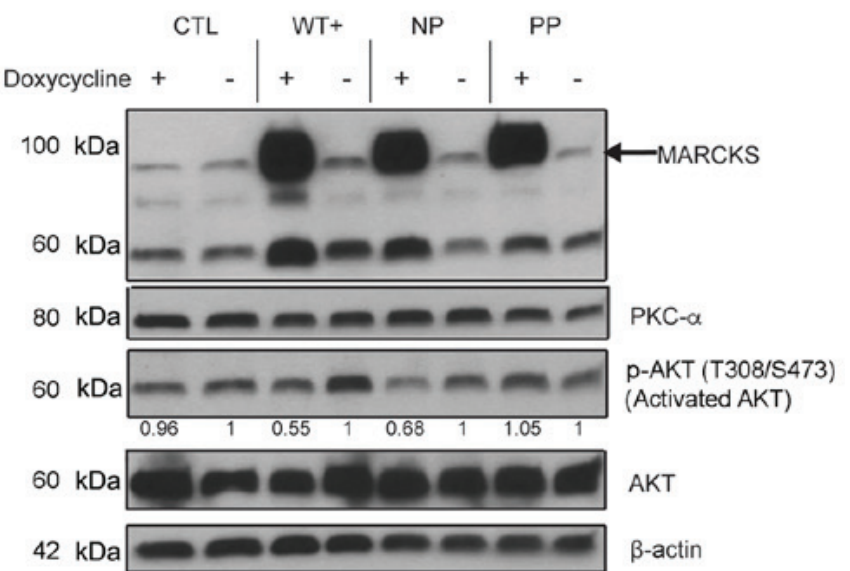

Figure 3. MARCKS ED phosphorylation overcomes the growth suppressive effects of MARCKS. (A) A total of 5,000 cells were plated in a black-walled 96 well plate with doxycycline and assessed for cell viability at day 7 using ATPlite assay ( $\mathrm{n}=12$ ). Comparison of mutants PBS vs. doxycycline induction is shown in Fig. S1. (B) Quantification of colonies at day 14 day containing >50 cells after plating 2,000 cells per plate. (C) Image of colony formation at day 14. (D) Magnified view of NP and PP colonies from colony formation 14 days after plating (x10 magnification). The solid arrows indicate example colonies. (E) A total of 5,000 cells were plated in a black-walled 96 well plate with doxycycline and assessed using CellTiter glow cell viability assay at 5 days in U373 $(\mathrm{n}=4)$. (F) Western blot analysis demonstrating the inducible nature of MARCKS expression 7 days after treating with $2 \mu \mathrm{g} / \mathrm{ml}$ doxycycline, and the effects on activated AKT (T308 and S473), AKT and PKC $\alpha$ expression. All probing done on same membrane with stripping. Cropped boundaries indicated by black line. Full-length blots and probing order are available in Fig. S5. Adjusted relative densitometry of p-AKT between Dox-induced and PBS un-induced (=1) calculated in ImageJ $(\mathrm{CTL}=0.962$, WT+=0.549, NP=0.678, PP=1.05). Statistical analysis was carried out in GraphPad Prism using $(\mathrm{A}$ and $\mathrm{B})$ ordinary one-way ANOVA with Dunnett's multiple comparison tests to CTL, or (E) two-tailed t-test. Data are the means $\pm \mathrm{SEM} .{ }^{* *} \mathrm{P}<0.01,{ }^{* * * *} \mathrm{P}<0.001$ and ${ }^{* * * * *} \mathrm{P}<0.0001$, compared to CTL. MARCKS, myristoylated alanine-rich C-kinase substrate; ED, effector domain; WT+, V5-tagged MARCKS vector; CTL, control; NP, non-phosphorylatable ED mutant; PP, pseudo-phosphorylated ED mutant; $\triangle E D$, deleted effector domain mutant.

effector domain mutant ( $\triangle \mathrm{ED})$ that lacks an ED (Fig. 2A). To evaluate the cellular localization of the MARCKS mutants, immunofluorescent imaging, and the analysis of the mutants $72 \mathrm{~h}$ following doxycycline induction were performed using the image cytometer Xcyto10. An unphosphorylated non- $\mathrm{Ca}^{2+} / \mathrm{CaM}$ bound ED is required for MARCKS membrane binding and F-actin crosslinking $(13,37)$ allowing $\triangle \mathrm{ED}$ to serve as a cytoplasmic control. MARCKS that co-localizes well with F-actin is consistent with an unphosphorylated ED, whereas MARCKS that co-localizes poorly with F-actin may indicate ED phosphorylation or binding to $\mathrm{Ca}^{2+} / \mathrm{CaM}$ (14). Imaging revealed WT+ and NP MARCKS to have substantial 
A

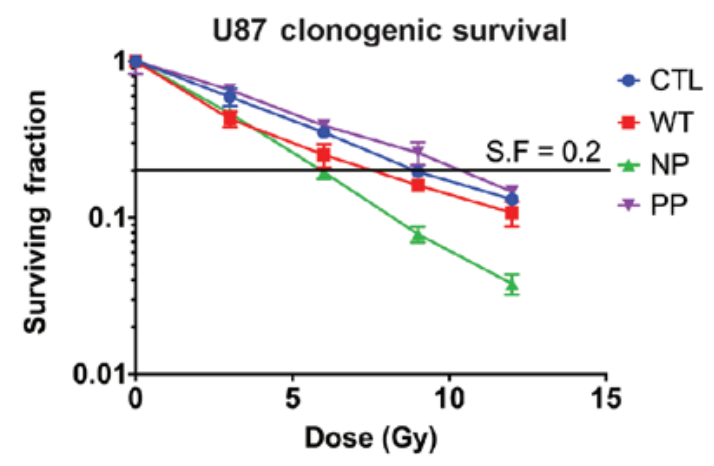

B

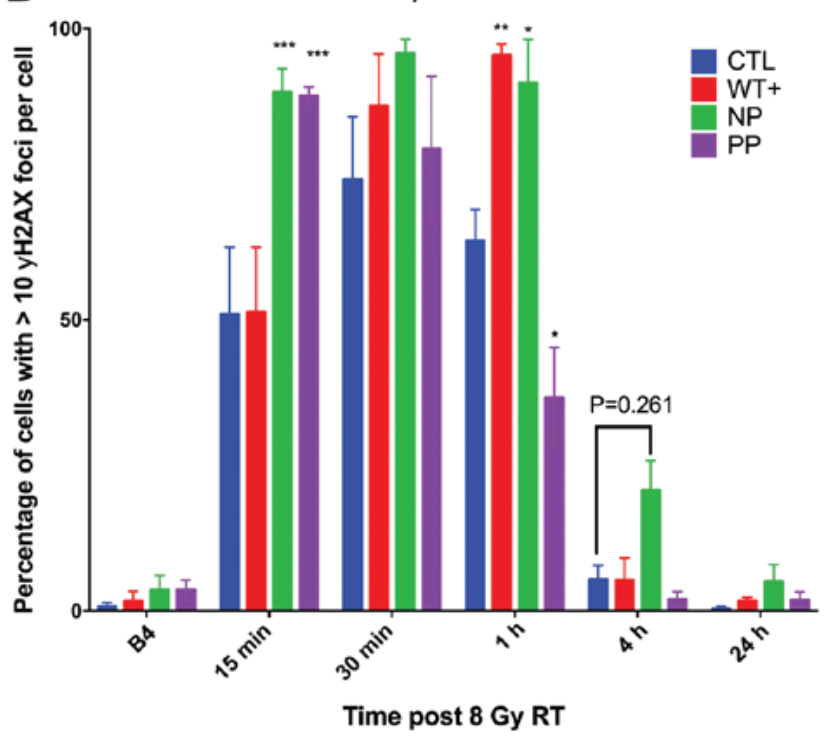

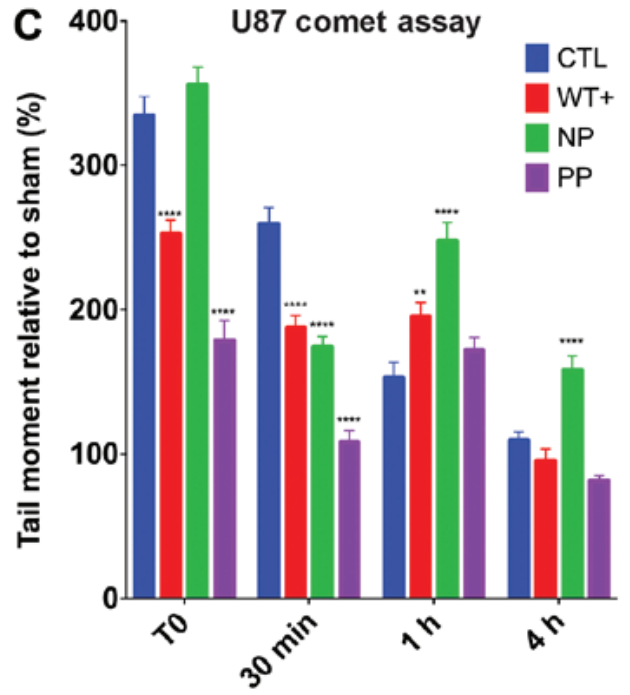

Time post 16 Gy RT

D

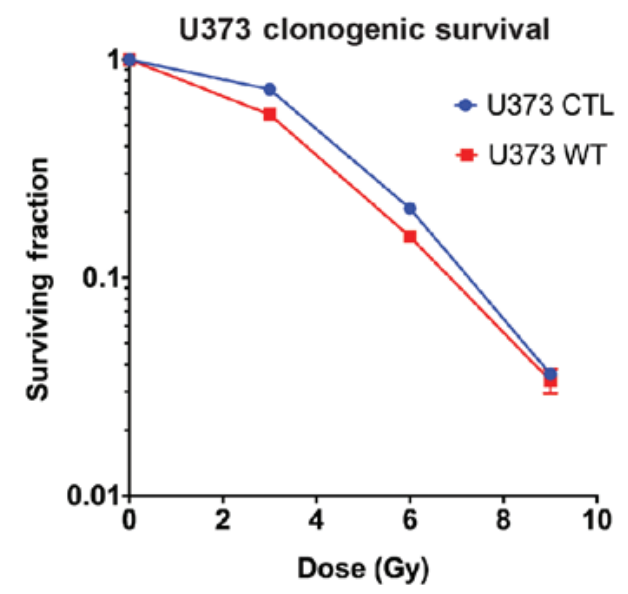

Figure 4. Unphosphorylated MARCKS ED is associated with greater radiation sensitivity in GBM. (A) Clonogenic survival assay of U87 MARCKS ED mutants receiving escalating doses of ionizing radiation plotted in a semilogarithmic manner with SEM error bars $(\mathrm{n}=4)$. (B) Mean nuclear $\mathrm{yH} 2 \mathrm{AX}$ intensity following 8 Gy RT measured in a blinded manner by counting the percentage of cells with greater than 10 foci per 20X field. (4 fields per measurement). (C) Quantification of double-strand DNA breaks following 16 Gy RT by measurement of comet tail moment (n>200). (D) Clonogenic survival assay of U373 dox 14 days after escalating doses of radiation ( $\mathrm{n}=3$ ). (B and C) Statistical analysis was carried out in GraphPad Prism using two-way ANOVA with Dunnett's multiple comparison tests to CTL. Data are the means \pm SEM. ${ }^{* * *} \mathrm{P}<0.01,{ }^{* * *} \mathrm{P}<0.001$ and ${ }^{* * * * *} \mathrm{P}<0.0001$, compared to CTL. MARCKS, myristoylated alanine-rich C-kinase substrate; ED, effector domain; WT+, V5-tagged MARCKS vector; CTL, control; NP, non-phosphorylatable ED mutant; PP, pseudo-phosphorylated ED mutant.

co-staining with phalloidin (F-actin stain), while the PP and $\triangle$ ED MARCKS lacked co-staining with F-actin and appeared predominantly cytoplasmic with perinuclear enrichment. Slight decreases in F-actin intensity were observed in all MARCKS mutants compared with the control (Fig. 2B). Fig. 2C highlights the differences in MARCKS staining between PP and $\triangle \mathrm{ED}$ with minimal $\mathrm{F}$-actin co-staining and prominent perinuclear staining, while NP shows substantial co-staining with F-actin (Fig. 2C). The quantification of MARCKS and F-actin co-staining revealed that both WT+ and NP MARCKS co-stained strongly with F-actin, while the CTL, PP and $\triangle E D$ lines did not (Fig. 2D). The imaging of uninduced MARCKS U87 mutants can be observed for comparison in Fig. S1. The overexpression of WT+ MARCKS in an additional PTEN-null line (U373) revealed that MARCKS was predominantly membrane-associated and perinuclear with a slight increase in actin co-localization (Fig. S2). These data indicate that the localization of WT+ and NP MARCKS mutants is consistent with an ED that is unphosphorylated and membrane-bound, while the PP mutant mimics the cytoplasmic localization of phosphorylated MARCKS.

MARCKS ED phosphorylation overcomes MARCKS growth suppression and promotes colony formation in vitro. To identify differences in GBM growth with MARCKS overexpression and the potential effects of ED phosphorylation, we measured the growth of our MARCKS mutants 7 days following doxycycline induction. Statistically significant $(\mathrm{P}<0.0001)$ decreases in growth were observed in the WT+ and NP mutants, and no decrease in growth in PP or $\triangle E D$ compared 
to the CTL line (Fig. 3A). The comparison of mutants under PBS and doxycycline conditions is available in Fig. S1 using ATPlite proliferation assay. Colony formation assays revealed NP MARCKS to trend towards $(\mathrm{P}=0.076)$ a decrease in colony number compared to CTL, while PP exhibited significant $(\mathrm{P}=0.001)$ increases in the number of colonies. WT+ $(\mathrm{P}=0.61)$ and $\triangle E D(P=0.85)$ exhibited no significant differences in colony number (Fig. 3B). Colonies formed by PP were also larger and contained more cells per colony on average compared with CTL and other mutants (Fig. 3C). A magnified view of NP and PP colony differences (solid arrow) can be seen in Fig. 3D. The orthotopic implantation of these ED mutants into mice, however, did not reveal significant differences in survival between the ED mutants, suggesting that MARCKS ED phosphorylation may not fully account for the MARCKS survival benefit (Fig. S3). The growth-suppressive effects of MARCKS overexpression (WT+) were additionally observed in the PTEN-null U373 GBM cell line (P=0.0010) (Fig. 3E), although we lacked NP and PP ED mutants in U373 for additional validation.

Both AKT activation (6) and PKC $\alpha$ protein expression (38) are associated with enhanced cancer growth, proliferation and survival signaling, and the knockdown of MARCKS in GBM has been previously shown to enhance AKT phosphorylation (33) and decrease PKC $\alpha$ levels (32). In this study, we examined the mechanisms through which the overexpression of MARCKS ED mutants affect these features and found that WT+ and NP MARCKS overexpression decreased the activation of AKT (T308 and S473 phosphorylation) by 45 and 32\%, respectively compared to the PBS-treated cells, while CTL and PP exhibited negligible suppression. No effects were observed on PKC $\alpha$ expression with the overexpression of our MARCKS mutants (Fig. 3F). Overall, we found that MARCKS overexpression (WT+) suppressed GBM growth and the data suggest that it is the unphosphorylated ED (NP), which suppresses growth and AKT activation, while the phosphorylated ED (PP) does not. Since differences in AKT activation suggest differences in radiation sensitivity (39), we then investigated the effects of MARCKS ED phosphorylation on radiation sensitivity.

MARCKS ED phosphorylation modifies GBM sensitivity to radiation. Previous experiments in our laboratory have demonstrated that the inhibition of MARCKS ED phosphorylation or the overexpression of NP MARCKS in a lung cancer line sensitized them to radiation $(35,40)$. The GBM data in this study demonstrated that the overexpression of WT+ MARCKS enhanced radiation sensitization in vivo. To determine the mechanisms through which the MARCKS ED phosphorylation state affects radiation sensitivity, we first assessed our mutants using a clonogenic assay. We found NP MARCKS mutants to have the lowest clonogenic survival following escalating doses of radiation, showing radiation sensitization compared with CTL. WT+ exhibited a mild enhancement in radiation sensitivity compared with the control, while PP exhibited slightly decreased sensitivity (dose enhancement ratios at surviving fraction 0.2: $\mathrm{CTL}=1$, $\mathrm{WT}+=1.2, \mathrm{~N}=1.5$ and $\mathrm{PP}=0.87$ ) (Fig. 4A). To investigate potential alterations in DNA repair, we then examined the phosphorylation of histone $\mathrm{H} 2 \mathrm{AX}$ at $\mathrm{S} 139(\gamma \mathrm{H} 2 \mathrm{AX})$ as a surrogate for DNA damage. At $1 \mathrm{~h}$ post- 8 Gy single fraction radiotherapy, the $\mathrm{WT}+(\mathrm{P}=0.0021)$ and $\mathrm{NP}(\mathrm{P}=0.0111)$ mutants exhibited prolonged increases in $\gamma \mathrm{H} 2 \mathrm{AX}$ levels compared with the control, whereas $\mathrm{PP}(\mathrm{P}=0.0116)$ exhibited a slight decrease. At $4 \mathrm{~h}$, no statistically significant increases in $\gamma \mathrm{H} 2 \mathrm{AX}$ were observed compared with CTL; however, NP did trend towards a significant increase $(\mathrm{P}=0.2609)$ (Fig. 4B). Due to the considerable radiation resistance of $\mathrm{U} 87$ cells and variations in the cell cycle that alter individual cell radiation sensitivity (41) we used an elevated 16 Gy dose of radiotherapy to directly quantify the formation and resolution of double-strand DNA (dsDNA) breaks using a neutral comet assay (Fig. 4C). NP exhibited the greatest and most significant increases in the tail moment compared to CTL both at $1 \mathrm{~h}(\mathrm{P}<0.0001)$ and $4 \mathrm{~h}$ $(\mathrm{P}=0.0012)$ post-irradiation compared with $\mathrm{CTL}$. WT+ had a lower basal amount of DNA damage immediately following 16 Gy (T0) and at $30 \mathrm{~min}$; however at $1 \mathrm{~h}$, WT+ displayed sustained DNA damage $(\mathrm{P}=0.0067)$ compared with the control. PP also had a lower induction of double-strand DNA damage immediately following RT and a similar return to baseline as the control (Fig. 4C). The overexpression of WT+ MARCKS in U373 GBM cells similarly revealed increased yH2AX nuclear staining (Fig. S1C) and RT sensitivity measured by clonogenic assay (Fig. 4D), although we lacked ED mutants for additional validation. These data support prior findings that MARCKS is involved in that DNA damage response $(33,40)$ and suggest that an unphosphorylated ED promotes MARCKS radiation sensitization in vitro.

IdentificationofMARCKSprotein-proteininteractionsin GBM using immunoprecipitation coupled to mass spectrometry. MARCKS is known to be phosphorylated by PKC and ROCK and dephosphorylated by protein phosphatase 2 (PP2A), which alter its ability to bind $\mathrm{Ptd} \operatorname{lns}(4,5) \mathrm{P}_{2}$, actin, and $\mathrm{Ca}^{2+} / \mathrm{CaM}(10)$. Recently, MARCKS ED has been shown to function as an NLS allowing it to translocate into the nucleus of GBM and bind nuclear Ptdlns $(4,5) \mathrm{P}_{2}$ (25). In this study, to identify novel protein-protein interactions of MARCKS in GBM, we immunoprecipitated MARCKS in the WT+ overexpressing U87 cell line and detected protein interactions with high-resolution mass spectrometry. The successful pulldown of MARCKS was verified by western blot analysis before proceeding with in-gel digestion, liquid chromatography and high-resolution mass spectrometry (Fig. 5A). A total of 275 proteins were detected in the two separate MARCKS IP that was not found in the IgG control, 108 of which were identified in both fractions (Fig. 5B). A GeneGo pathway analysis map was constructed from these 108 proteins showing only direct protein interactions (Fig. 5C). A common pathway map was similarly generated in GeneGo to determine the potential signaling interactions of MARCKS (Fig. 5D). The top protein pathway interactions found were involved in cytoskeletal remodeling and the regulation of the actin cytoskeleton and non-homologous end joining (NHEJ) DNA repair pathway. Notable direct protein interactions of interest with MARCKS found using this technique include importin $\beta-2$ (transportin-1), a nuclear import chaperone that binds nuclear localization sequences, and $\mathrm{Ku} 70$, a protein involved in DNA repair. However, additional validation of these targets at endogenously expressed MARCKS levels is still required. 
A

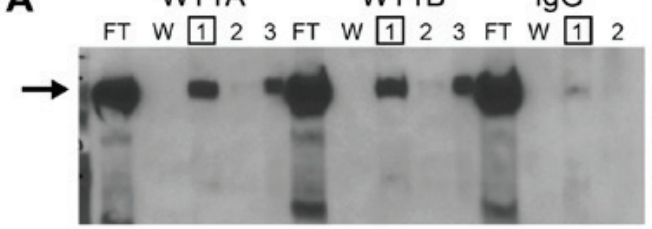

IP: MARCKS rabbit

WB: MARCKS mouse

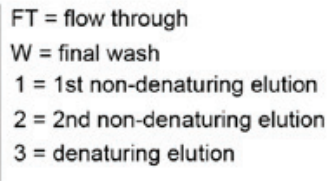

$2=2$ nd non-denaturing elution $3=$ denaturing elution

\section{C}

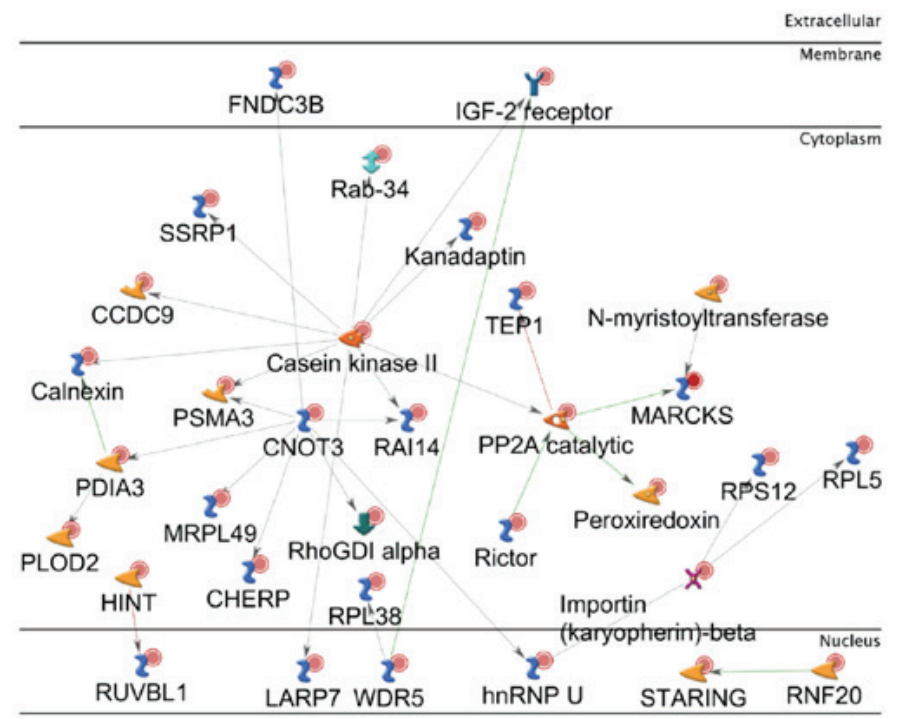

B

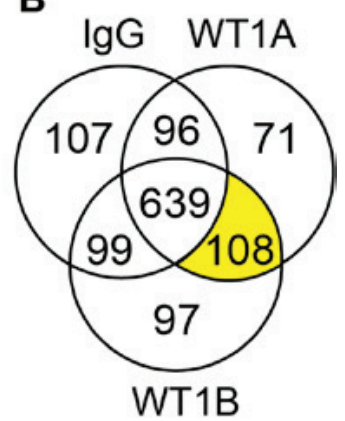

\begin{tabular}{|c|c|c|c|c|c|c|}
\hline \# & Maps & Total & P-value & $\begin{array}{l}\text { Min } \\
\text { FDR }\end{array}$ & $\begin{array}{c}\text { In } \\
\text { Data }\end{array}$ & Network Objects from Data \\
\hline & $\begin{array}{l}\text { Cytoskeleton remodeling Regulation of actin cytoskeieton } \\
\text { organization by the kinase effectors of Rho GTPases }\end{array}$ & 58 & 0.0015 & 0.1353 & 3 & RhoGDI alpha, LIMK1, LIMK \\
\hline 2 & DNA damage_NHEJ mechanisms of DSBs repair & 19 & 0.0025 & 0.1353 & 2 & $\begin{array}{l}\text { Ku70, Casein kinase II, beta chain } \\
\text { (Phosvitin) }\end{array}$ \\
\hline & $\begin{array}{l}\text { DNA damage Inhibition of telomerase activity and ceilular } \\
\text { senescence }\end{array}$ & 20 & 0.0028 & 0.1353 & 2 & TEP1, PP2A catalytic \\
\hline 4 & Development_Slit-Robo signaling & 30 & 0.0062 & 0.2266 & 2 & CRMP2, LIMK1 \\
\hline & $\begin{array}{l}\text { Development Regulation of telomere length and cellular } \\
\text { immortalization }\end{array}$ & 35 & 0.0084 & 0.2273 & 2 & TEP1, Ku70 \\
\hline 6 & Development_MAG-dependent inhibition of neurite outgrowth & 37 & 0.0093 & 0.2273 & 2 & RhoGDI alpha, LIMK1 \\
\hline & $\begin{array}{l}\text { Neurophysiological process Receptor-mediated axon growth } \\
\text { repulsion }\end{array}$ & 46 & 0.0142 & 0.2399 & 2 & CRMP2, LIMK1 \\
\hline 8 & Signal transduction_Ca/cium signaling & 46 & 0.0142 & 0.2399 & 2 & RhoGDI alpha, PP2A catalytic \\
\hline & $\begin{array}{l}\text { Immune response_MIF - the neuroendocrine-macrophage } \\
\text { connector }\end{array}$ & 47 & 0.0148 & 0.2399 & 2 & PRDX1, PP2A catalytic \\
\hline & $\begin{array}{l}\text { Immune response_Antigen presentation by MHC class I, } \\
\text { classicai pathway }\end{array}$ & 54 & 0.0192 & 0.2701 & 2 & PDIA3, Cainexin \\
\hline & Regulation of CFTR activity (normal and CF) & 62 & 0.0249 & 0.2701 & 2 & $\begin{array}{l}\text { Casein kinase II, beta chain (Phosvitin). } \\
\text { PP2A catalytic }\end{array}$ \\
\hline & Signal transduction_mTORC2 upstream signaling & 65 & 0.0272 & 0.2701 & 2 & Rictor, RPL5 \\
\hline & $\begin{array}{l}\text { Development_Positive regulation of STK } 3 / 4 \text { (Hippo) pathway } \\
\text { and negative regulation of YAP/TAZ function }\end{array}$ & 70 & 0.0312 & 0.2701 & 2 & RhoGDI alpha, PEZ \\
\hline 14 & Signal transduction_mTORC1 upstream signaling & 74 & 0.0346 & 0.2701 & 2 & PDIA3, MAG1 \\
\hline 15 & Ubiquinone metabolism & 74 & 0.0346 & 0.2701 & 2 & NDUFA4, NDUFS6 \\
\hline & $\begin{array}{l}\text { Development_NCAM1-mediated neurite outgrowth, synapse } \\
\text { assembly and neuronal survival }\end{array}$ & 75 & 0.0354 & 0.2701 & 2 & LiMK1, Casoin kinase II \\
\hline 17 & Transport_Rab-9 regulation pathway & 10 & 0.0389 & 0.2701 & 1 & IGF-2 receptor \\
\hline 18 & Transport_Macropinocytosis & 12 & 0.0465 & 0.2701 & 1 & Rab-34 \\
\hline
\end{tabular}

Figure 5. MARCKS protein-protein interactions identified by immunoprecipitation coupled with in-gel digestion, liquid chromatography, and high-resolution mass spectrometry. U87 WT+ was doxycycline-induced for $72 \mathrm{~h}$ before lysis using MPER. (A) immunoprecipitation was performed in WT+ lysate with catch and release V2.0 system and MARCKS rabbit pAB or IgG rabbit control antibody. Successful IP was confirmed by western blot analysis using MARCKS mouse monoclonal antibody. (B) Venn diagram of 108 unique proteins detected in 2 separate MARCKS IP's not found in IgG control. Scaffold_4.6.2 was used to generate the graph. Protein threshold (80\%), Min \# peptides (1), Peptide threshold (80\%). (C) network map or (D) pathway map generated from the 108 unique proteins using GeneGo 4.9.18 plotting direct interactions and exclusion of orphan nodes. MARCKS, myristoylated alanine-rich C-kinase substrate; WT+, V5-tagged MARCKS vector.

\section{Discussion}

GBM remains a devastating disease driven by high rates of growth, therapeutic resistance and invasiveness, which ultimately results in recurrence. Developing a better understanding of the molecular mechanisms that contribute to this aggressiveness is essential to developing future effective therapeutic strategies. Over $80 \%$ of GBM cases 
contain activating mutations in RTKs/PI3K/AKT or the loss of PTEN (6). These mutations all contribute to dysregulations in Ptdlns $(4,5) \mathrm{P}_{2}$ signaling, which promotes cell proliferation, differentiation $(42,43)$, invasion (32) and therapeutic resistance (44-46) pathways, rendering this signaling axis an ideal therapeutic target $(6,47)$. To date, however, small molecule inhibitors targeting this pathway have had minimal success in GBM $(48,49)$. One potential reason for this failure lies in an incomplete understanding of regulators of this pathway, such as MARCKS (10). MARCKS is a well-known regulator of Ptdlns $(4,5) \mathrm{P}_{2}$ levels (50-52), which plays a vital role in AKT activation that drives cell proliferation, chemoand radiation resistance $(45,46,53)$. MARCKS expression has had a confusing association with both positive and negative prognosis across different cancer types (10,26-28,54,55), and this ambiguity over the role of MARCKS in cancer has been attributed to potential differences MARCKS ED phosphorylation $(10,30,56)$. The phosphorylation of MARCKS ED by PKC or ROCK kinases results in the translocation of MARCKS off the plasma membrane, prevents its binding to PS (24), $\mathrm{Ca}^{2+} /$ calmodulin and crosslinking of actin filaments, and releases sequestered Ptdlns(4,5) $\mathrm{P}_{2}(18,57,58)$. MARCKS ED also serves as an NLS (25), and differences in its phosphorylation are also likely to regulate nuclear import. Indeed, we detected differences in the nuclear localization of our PP ED mutant from WT+ and NP ED mutant that needs additional future validation in a model system with endogenous MARCKS expression (Fig. S4). Due to the important role of Ptdlns (4,5) $\mathrm{P}_{2}$ in oncogenic signaling (8), the frequent mutations of GBM altering Ptdlns $(4,5) \mathrm{P}_{2}$ signaling (6), and the role of MARCKS in regulating Ptdlns $(4,5) \mathrm{P}_{2}$ availability (59), in this study, we evaluated the effects of MARCKS expression and ED phosphorylation on GBM growth and therapeutic resistance.

The current study supports previous in vitro findings that the loss of MARCKS enhances growth and radiation resistance in a PTEN-null GBM line (33). Through the overexpression of WT+ MARCKS in an intracranial tumor model, we further established MARCKS expression enhanced survival and radiation responses compared to empty vector control (CTL) mice. To determine the mechanisms through which the phosphorylation of MARCKS ED may alter these tumor-suppressing effects, we mimicked ED phosphorylation or prevented phosphorylation through substitution of the 4 ED serine residues. MARCKS functions as an electrostatic switch based on it ED phosphorylation status (13), with F-actin and plasma membrane binding with an unphosphorylated ED, and the loss of F-actin membrane binding after phosphorylation. Additionally, $\triangle E D$ functions as a cytoplasmic control as the ED contains both the actin-binding domain and the poly-lysine $(+13)$ electrostatic attraction to the plasma membrane (13). The ED mutants were found to appropriately mimic MARCKS ED phosphorylation state with NP co-localizing with F-actin at the plasma membrane, while PP and $\triangle E D$ mutants localized to the cytoplasmic and perinuclear region. WT+ closely mimicked NP with high levels of F-actin co-localization and similar morphologic appearance suggesting the majority of overexpressed MARCKS was membrane-bound. Although slight decreases in filamentous actin staining were observed following the overexpression of
MARCKS in all our mutant lines compared with control or uninduced group, no substantial differences existed between the ED mutants. This suggested cytoskeletal impairment was not a major factor in the phenotypic differences of our mutants.

We then examined the effects of MARCKS ED phosphorylation on GBM growth by measuring its effects on cell viability using ATP luminescence (60). To control for potential metabolic disturbances occurring from lentiviral transduction or doxycycline exposure we used the empty vector CTL line for comparison of the effects of MARCKS ED mutant expression. We found the WT+ and NP MARCKS overexpression led to significant decreases in cell viability $(\mathrm{P}<0.0001)$, while the PP or $\triangle \mathrm{ED}$ mutants did not suppress viability. The significant suppression of cell viability in WT+ and $\mathrm{NP}(\mathrm{P}=0.004$ and $\mathrm{P}=0.0093$, respectively) was dependent on exposure of the mutants to doxyxcline, and its resulting expression of mutant MARCKS protein, with no significant decreases in viability seen in CTL or PP as observed in Fig. S1B. The cytotoxic effects of MARCKS expression were not observed; thus, this decreased cell viability was attributed to decreased proliferation. Although ATP levels are a reliable measure of metabolic viability and typically, cell number, ATP can also be altered by circadian rhythms, proliferation and differentiation, which we did not differentiate from (61). We utilized the colony formation assay as a second assay for investigating MARCKS growth effects.

Colony formation assay, which estimates the proportion of cells capable of 'unlimited' replication, revealed that NP trended towards a decrease in colony forming ability, while PP significantly enhanced colony formation. This increased number and size of the colonies would indicate that PP MARCKS may enhance the proliferative capacity of GBM. Differential growth effects of MARCKS have previously described in epithelial and vascular smooth muscle cells, although differences in ED phosphorylation status were not investigated (62). However, testing in vivo failed to reveal statistically significant differences in the median survival (one-way ANOVA $\mathrm{P}=0.0879$ ) or mitotic counts (one-way ANOVA $\mathrm{P}=0.1587$ ) between MARCKS mutants and control. This suggests ED phosphorylation may have a less definitive roll in affecting overall survival. The weak correlation of mitotic counts to survival time is confounded by the fact mitotic counts were acquired at the time of sacrificing opposed to a similar timepoint. Potential reasons for these in vivo, in vitro differences, include MARCKS ED phosphorylation may function more in releasing MARCKS inhibition on the proliferative capacity than directly driving proliferation, especially under the different microenvironmental conditions, such as limited nutrient and oxygen availability of the intracranial growth environment. Additionally, MARCKS may enhance survival in GBM ways not directly altered by ED phosphorylation. The investigation of MARCKS ED phosphorylation on p-AKT (T308/S473) revealed WT+ and NP MARCKS overexpression suppressed p-AKT levels, while PP MARCKS did not in GBM. These data support other findings that ED phosphorylation is an important regulator of this pathway (10). No effect was observed on PKC $\alpha$ expression with or MARCKS overexpression model as previously reported in a GBM EGFR-VIII line, suggesting that EGFR-VIII expression may be essential for MARCKS-driven PKC $\alpha$ expression differences (32). 
MARCKS knockdown was previously shown to enhance the NHEJ DNA repair mechanism and radiation resistance in GBM (33). Consistent with this, in this study, we found that MARCKS overexpression (WT+) in U87 and U373 cells increased radiation sensitivity. Investigating the effects of ED phosphorylation on MARCKS radiation sensitization, we found that the NP mutant was radiation-sensitive by clonogenic assay, $\gamma \mathrm{H} 2 \mathrm{AX}$, and comet assay, while the PP mutant was not. The clonogenic assay measures the cumulative effects of radiation on survival,including celldeath,senescence, metabolicdisturbances, that may take generations to develop and is considered the most sensitive in vitro radiation sensitivity assay (63). NP was found to have a prolonged presence of $\gamma \mathrm{H} 2 \mathrm{AX}$ quantified as a percentage of cells with $>10$ foci per cell. However, the PP mutant revealed prolonged $\gamma \mathrm{H} 2 \mathrm{AX}$ staining in some instances when quantified by mean nuclear intensity (Fig. S1), although this result was inconsistent with the comet assay, clonogenic assay findings, and traditional foci count methodology. The high level of radiation resistance by U87 cells (41) and the differences in sensitivity between $\gamma \mathrm{H} 2 \mathrm{AX}$ quantification methods may account for these differences, which can be minimized with higher doses or radiation (64). Higher $16 \mathrm{~Gy}$ doses of radiotherapy were needed for significant neutral comet assay results. NP also exhibited the most prolonged increase in dsDNA breaks following RT, most closely reflecting the clonogenic assay findings in suggesting it is radiation sensitive. Immediately following irradiation (T0), WT and PP showed lower levels of dsDNA, however, at $1 \mathrm{~h}$ WT+ also exhibited a significant $(\mathrm{P}=0.0067)$ elevation of DNA damage relative to the control, while PP did not. As such, we propose that the membrane-bound, unphosphorylated form of MARCKS promotes radiation sensitization.

Utilizing IP/MS of MARCKS in U87 cells, we identified known MARCKS interactors including PP2A, known to dephosphorylate MARCKS ED, and $\mathrm{N}$-myristoyltransferase (NMT) which preferentially myristoylated MARCKS over many other myristoylated proteins (65). These exploratory studies suggest a number of new interacting partners that can be validated in future studies. Rho GTPases including LIMK1 and Rho GDP-dissociation inhibitor 1 were also detected and are important regulators of the actin cytoskeleton promoting cell migration (66). We detected a notable interaction with transportin-1a nuclear import protein that regulates nuclear-cytoplasmic transport through adapter proteins (67). Transportin-1 and MARCKS interactions are previously unreported, but are consistent with emerging data that MARCKS is selectively imported into the nucleus in specific cell types (68), and our findings that only the PP mutant was not enriched in the nucleus suggests ED phosphorylation may inhibit its translocation through the nuclear membrane. Interaction with casein kinase 2 (CK2) and its central location in MARCKS protein network suggest it may also directly regulate MARCKS at the ED or other phosphorylation domains. CK2 has previously been shown to phosphorylate proteins regulating their nuclear localization (69), regulate the cell cycle, NHEJ DNA repair and WNT signaling (70), and mediate non-canonical WNT signaling through PKC $\Delta$ (71). Several interactions with nuclear proteins were detected that were involved in DNA repair including XRCC6 (Ku70), TEP1 and SSRP1, suggesting that MARCKS may play a direct role in DNA repair mechanism beyond $\operatorname{Ptdlns}(4,5) \mathrm{P}_{2}$ sequestration.
Perinuclear proteins involved in endoplasmic reticulum calcium homeostasis including CHERP and TRAPG were identified, along with Myoferlin, a calcium/phospholipid binding-protein with a role in plasmalemma repair. Lastly, MARCKS has previously been shown to become phosphorylated by elevated levels of $\mathrm{H}_{2} \mathrm{O}_{2}$ in a PKC $\Delta$ dependent manner (72). The potential interaction with peroxiredoxin 1a, a regulator of intracellular $\mathrm{H}_{2} \mathrm{O}_{2}$ signaling previously shown to be involved in promoting invasion, radiation and chemotherapy resistance (73), further strengthens the relationship of $\mathrm{H}_{2} \mathrm{O}_{2}$ signaling and MARCKS. Future studies investigating $\mathrm{H}_{2} \mathrm{O}_{2}$ effects on GBM growth and invasion should be considered due to $\mathrm{H}_{2} \mathrm{O}_{2}$ use during GBM resection for tumoricidal effects (74). $\mathrm{H}_{2} \mathrm{O}_{2}$ use at subtherapeutic levels may in theory trigger invasive and proliferative effects seen with MARCKS phosphorylation (32).

The limitations of this study include the use of a doxycycline-inducible model with overexpression of MARCKS ED mutants, as opposed to testing at endogenous MARCKS levels with true serine phosphorylation, and the lack of additional NP and PP ED mutants that could be tested in PTEN null cell lines. Due to the dynamic and differential effects MARCKS ED can have in regulating cellular functions (62), the impact of MARCKS expression and ED phosphorylation should be carefully considered in other model systems and signaling environments, such as serum-free growth conditions to establish the effects of MARCKS.

In conclusion, the intrinsically unstructured nature and electrostatic properties of MARCKS allow it to have a broad range of cellular interactions regulated by its centrally located 25 amino acid ED. At a minimum, MARCKS ED binds or responds to: $\mathrm{Ptdlns}(4,5) \mathrm{P}_{2}$ (19), phosphatidylserine (24), F-actin crosslinking (58), phosphorylation by PKC and ROCK kinases and binding to $\mathrm{Ca}^{2+} /$ calmodulin (10), intracellular calcium levels (13), and $\mathrm{H}_{2} \mathrm{O}_{2}$ signaling (72) allowing it to coordinate cellular functions, such as vesicle release (75), cell migration (76), proliferation and differentiation $(42,43,62)$. MARCKS plays a potential role in cancer stemness that needs future evaluation (77). Prior to this study, MARCKS knockdown was associated with enhanced GBM growth and radiation resistance (33), and the phosphorylation of MARCKS ED was associated with enhanced invasion (32) with an undetermined effect on growth and radiation sensitivity in GBM. This study investigated the mechanisms through which ED phosphorylation regulates MARCKS cellular localization, and in turn, examined the effects of MARCKS on growth suppression and radiation sensitivity in PTEN-null GBM. We find that NP MARCKS to exhibited a similar suppression of growth and AKT activation and enhancement radiation sensitivity as WT+ overexpression, while the PP mutant did not exhibit these features. This study suggests that MARCKS ED phosphorylation may be a method with which to overcome MARCKS growth-suppressing and radiation-sensitizing effects and that the determination of the ED phosphorylation status is vital to understanding the potential effects of MARCKS expression.

\section{Acknowledgements}

The authors would like to thank Brandon Young at the UAB comprehensive cancer center mass spectrometry core for his assistance with the mass spectrometry analysis. 


\section{Funding}

This study was supported by funding from the National Institutes of Health (the UAB MSTP training grant: T32GM008361 and the UAB Training Program in Brain Tumor Biology: T32NS048039), the American Cancer Society through a Research Scholar Grant (Grant no. RSG-14-071-01-TBG), as well as by an intramural research grant from the UAB Department of Radiation Oncology.

\section{Availability of data and materials}

All data generated or analyzed during this study are included in this published article.

\section{Authors' contributions}

CDW, NJE and GYG conceived and designed the study. CDW, ABH, GYG, NJE, CPL, JAM, JRH, RTP, JCA, JSJ and JAB developed the methodology. GYG, NJE, CPL, HQT, KC, JAM, JRH, JCA and PHH acquired the data. CDW, ABH, GYG, NJE, CPL, HQT, JAM, JRH, RTP, JCA, PHH and JAB analyzed and interpreted the data. All authors reviewed the manuscript. All authors have read and approved the final manuscript.

\section{Ethics approval and consent to participate}

All animal studies were carried out in accordance with the policies set by the University of Alabama (UAB) Institutional Animal Care and Use Committee (IACUC) and performed according to their guidelines. The experimental protocols were registered and approved by the UAB Occupational Health and Safety (project no. 14-124).

\section{Patient consent for publication}

Not applicable.

\section{Competing interests}

RTP is an employee at ChemoMetec and assisted in the use of Xcyto10, aided in Xcyto10 data analysis, and reviewed the manuscript. ChemoMetec provided the Xcyto10 microscope on loan and also provided microscope slides, Blue MASK, and DAPI reagents but no financial compensation. The other authors declare no competing interests.

\section{References}

1. Li YM, Suki D, Hess K and Sawaya R: The influence of maximum safe resection of glioblastoma on survival in 1229 patients: Can we do better than gross-total resection? J Neurosurg 124: 977-988, 2016.

2. Johnson DR and O'Neill BP: Glioblastoma survival in the United States before and during the temozolomide era. J Neurooncol 107: 359-364, 2012.

3. Stupp R, Mason WP, van den Bent MJ, Weller M, Fisher B, Taphoorn MJ, Belanger K, Brandes AA, Marosi C, Bogdahn U, et al; European Organisation for Research and Treatment of Cancer Brain Tumor and Radiotherapy Groups; National Cancer Institute of Canada Clinical Trials Group: Radiotherapy plus concomitant and adjuvant temozolomide for glioblastoma. N Engl J Med 352: 987-996, 2005.
4. Mao H, Lebrun DG, Yang J, Zhu VF and Li M: Deregulated signaling pathways in glioblastoma multiforme: Molecular mechanisms and therapeutic targets. Cancer Invest 30: 48-56, 2012.

5. Ceccarelli M, Barthel FP, Malta TM, Sabedot TS, Salama SR, Murray BA, Morozova O, Newton Y, Radenbaugh A, Pagnotta SM, et al; TCGA Research Network: Molecular Profiling Reveals Biologically Discrete Subsets and Pathways of Progression in Diffuse Glioma. Cell 164: 550-563, 2016.

6. Li X, Wu C, Chen N, Gu H, Yen A, Cao L, Wang E and Wang L: $\mathrm{PI} 3 \mathrm{~K} / \mathrm{Akt} / \mathrm{mTOR}$ signaling pathway and targeted therapy for glioblastoma. Oncotarget 7: 33440-33450, 2016.

7. Jhanwar-Uniyal M, Amin AG, Cooper JB, Das K, Schmidt MH and Murali R: Discrete signaling mechanisms of mTORC1 and mTORC2: Connected yet apart in cellular and molecular aspects. Adv Biol Regul 64: 39-48, 2017.

8. Denley A, Gymnopoulos M, Kang S, Mitchell C and Vogt PK: Requirement of phosphatidylinositol $(3,4,5)$ trisphosphate in phosphatidylinositol 3-kinase-induced oncogenic transformation. Mol Cancer Res 7: 1132-1138, 2009.

9. Ramos AR, Elong Edimo W and Erneux C: Phosphoinositide 5-phosphatase activities control cell motility in glioblastoma: Two phosphoinositides $\mathrm{PI}(4,5) \mathrm{P} 2$ and $\mathrm{PI}(3,4) \mathrm{P} 2$ are involved. Adv Biol Regul 67: 40-48, 2018.

10. Fong LWR, Yang DC and Chen CH: Myristoylated alanine-rich $\mathrm{C}$ kinase substrate (MARCKS): A multirole signaling protein in cancers. Cancer Metastasis Rev 36: 737-747, 2017.

11. Guan Y, Zhu Q, Huang D, Zhao S, Jan Lo L and Peng J: An equation to estimate the difference between theoretically predicted and SDS PAGE-displayed molecular weights for an acidic peptide. Sci Rep 5: 13370, 2015.

12. Ramsden JJ: MARCKS: A case of molecular exaptation? Int J Biochem Cell Biol 32: 475-479, 2000.

13. Arbuzova A, Schmitz AA and Vergères G: Cross-talk unfolded: MARCKS proteins. Biochem J 362: 1-12, 2002.

14. Brudvig JJ and Weimer JM: X MARCKS the spot: Myristoylated alanine-rich $\mathrm{C}$ kinase substrate in neuronal function and disease. Front Cell Neurosci 9: 407, 2015.

15. Tapp H, Al-Naggar IM, Yarmola EG, Harrison A, Shaw G, Edison AS and Bubb MR: MARCKS is a natively unfolded protein with an inaccessible actin-binding site: Evidence for long-range intramolecular interactions. J Biol Chem 280: 9946-9956, 2005.

16. Arbuzova A, Wang J, Murray D, Jacob J, Cafiso DS and McLaughlin S: Kinetics of interaction of the myristoylated alanine-rich $\mathrm{C}$ kinase substrate, membranes, and calmodulin. J Biol Chem 272: 27167-27177, 1997.

17. Hartwig JH, Thelen M, Rosen A, Janmey PA, Nairn AC and Aderem A: MARCKS is an actin filament crosslinking protein regulated by protein kinase $\mathrm{C}$ and calcium-calmodulin. Nature 356: 618-622, 1992.

18. Yarmola EG, Edison AS, Lenox RH and Bubb MR: Actin filament cross-linking by MARCKS: Characterization of two actin-binding sites within the phosphorylation site domain. J Biol Chem 276: 22351-22358, 2001.

19. Wang J, Arbuzova A, Hangyás-Mihályné G and McLaughlin S: The effector domain of myristoylated alanine-rich $\mathrm{C}$ kinase substrate binds strongly to phosphatidylinositol 4,5-bisphosphate. J Biol Chem 276: 5012-5019, 2001.

20. Zhang W, Crocker E, McLaughlin S and Smith SO: Binding of peptides with basic and aromatic residues to bilayer membranes: Phenylalanine in the myristoylated alanine-rich $\mathrm{C}$ kinase substrate effector domain penetrates into the hydrophobic core of the bilayer. J Biol Chem 278: 21459-21466, 2003.

21. Thelen M, Rosen A, Nairn AC and Aderem A: Regulation by phosphorylation of reversible association of a myristoylated protein kinase $\mathrm{C}$ substrate with the plasma membrane. Nature 351: 320-322, 1991

22. Tanabe A, Kamisuki Y, Hidaka H, Suzuki M, Negishi M and Takuwa Y: PKC phosphorylates MARCKS Ser159 not only directly but also through RhoA/ROCK. Biochem Biophys Res Commun 345: 156-161, 2006.

23. Denisov G, Wanaski S, Luan P, Glaser M and McLaughlin S: Binding of basic peptides to membranes produces lateral domains enriched in the acidic lipids phosphatidylserine and phosphatidylinositol 4,5-bisphosphate: An electrostatic model and experimental results. Biophys J 74: 731-744, 1998.

24. Nakaoka T, Kojima N, Ogita T and Tsuji S: Characterization of the phosphatidylserine-binding region of rat MARCKS (myristoylated, alanine-rich protein kinase $\mathrm{C}$ substrate). Its regulation through phosphorylation of serine 152. J Biol Chem 270: 12147-12151, 1995. 
25. Rohrbach TD, Shah N, Jackson WP, Feeney EV, Scanlon S, Gish R, Khodadadi R, Hyde SO, Hicks PH, Anderson JC, et al: The effector domain of MARCKS is a nuclear localization signal that regulates cellular PIP2 levels and nuclear PIP2 localization. PLoS One 10: e0140870, 2015.

26. Bickeböller M, Tagscherer KE, Kloor M, Jansen L, ChangClaude J, Brenner H, Hoffmeister M, Toth C, Schirmacher P, Roth W, et al: Functional characterization of the tumor-suppressor MARCKS in colorectal cancer and its association with survival Oncogene 34: 1150-1159., 2015.

27. Brooks G, Brooks SF and Goss MW: MARCKS functions as a novel growth suppressor in cells of melanocyte origin. Carcinogenesis 17: 683-689, 1996.

28. Hanada S, Kakehashi A, Nishiyama N, Wei M, Yamano S, Chung K, Komatsu H, Inoue $\mathrm{H}$, Suehiro $\mathrm{S}$ and Wanibuchi $\mathrm{H}$ : Myristoylated alanine-rich C-kinase substrate as a prognostic biomarker in human primary lung squamous cell carcinoma. Cancer Biomark 13: 289-298, 2013.

29. Manenti S, Malecaze F, Chap H and Darbon JM: Overexpression of the myristoylated alanine-rich $\mathrm{C}$ kinase substrate in human choroidal melanoma cells affects cell proliferation. Cancer Res 58: 1429-1434, 1998.

30. Chen CH, Cheng CT, Yuan Y, Zhai J, Arif M, Fong LW, Wu R and Ann DK: Elevated MARCKS phosphorylation contributes to unresponsiveness of breast cancer to paclitaxel treatment. Oncotarget 6: 15194-15208, 2015.

31. Chen CH, Fong LWR, Yu E, Wu R, Trott JF and Weiss RH: Upregulation of MARCKS in kidney cancer and its potential as a therapeutic target. Oncogene 36: 3588-3598, 2017.

32. Micallef J, Taccone M, Mukherjee J, Croul S, Busby J, Moran MF and Guha A: Epidermal growth factor receptor variant III-induced glioma invasion is mediated through myristoylated alanine-rich protein kinase $\mathrm{C}$ substrate overexpression. Cancer Res 69: 7548-7556, 2009.

33. Jarboe JS, Anderson JC, Duarte CW, Mehta T, Nowsheen S, Hicks PH, Whitley AC, Rohrbach TD, McCubrey RO, Chiu S, et al: MARCKS regulates growth and radiation sensitivity and is a novel prognostic factor for glioma. Clin Cancer Res 18: 3030-3041, 2012.

34. Cerami E, Gao J, Dogrusoz U, Gross BE, Sumer SO, Aksoy BA, Jacobsen A, Byrne CJ, Heuer ML, Larsson E, et al: The cBio cancer genomics portal: An open platform for exploring multidimensional cancer genomics data. Cancer Discov 2: 401-404, 2012.

35. Rohrbach TD, Jones RB, Hicks PH, Weaver AN, Cooper TS Eustace NJ, Yang ES, Jarboe JS, Anderson JC and Willey CD MARCKS phosphorylation is modulated by a peptide mimetic of MARCKS effector domain leading to increased radiation sensitivity in lung cancer cell lines. Oncol Lett 13: 1216-1222, 2017.

36. Bradley JD, Kataoka Y, Advani S, Chung SM, Arani RB, Gillespie GY, Whitley RJ, Markert JM, Roizman B, Weichselbaum RR: Ionizing radiation improves survival in mice bearing intracranial high-grade gliomas injected with genetically modified herpes simplex virus. Clin Cancer Res 5: 1517-1522, 1999.

37. Arbuzova A, Murray D and McLaughlin S: MARCKS, membranes, and calmodulin: Kinetics of their interaction. Biochim Biophys Acta 1376: 369-379, 1998.

38. Cameron AJ, Procyk KJ, Leitges M and Parker PJ: PKC alpha protein but not kinase activity is critical for glioma cell proliferation and survival. Int J Cancer 123: 769-779, 2008

39. Li HF, Kim JS and Waldman T: Radiation-induced Akt activation modulates radioresistance in human glioblastoma cells. Radiat Oncol 4: 43, 2009.

40. Rohrbach TD, Jarboe JS, Anderson JC, Trummell HQ, Hicks PH, Weaver AN, Yang ES, Oster RA, Deshane JS, Steele C, et al Targeting the effector domain of the myristoylated alanine rich C-kinase substrate enhances lung cancer radiation sensitivity. Int J Oncol 46: 1079-1088, 2015.

41. Naidu MD, Mason JM, Pica RV, Fung H and Peña LA: Radiation resistance in glioma cells determined by DNA damage repair activity of Ape1/Ref-1. J Radiat Res (Tokyo) 51: 393-404, 2010.

42. Moon SH, Kim DK, Cha Y, Jeon I, Song J and Park KS: PI3K/Akt and Stat 3 signaling regulated by PTEN control of the cancer stem cell population, proliferation and senescence in a glioblastoma cell line. Int J Oncol 42: 921-928, 2013.

43. Peltier J, O'Neill A and Schaffer DV: PI3K/Akt and CREB regulate adult neural hippocampal progenitor proliferation and differentiation. Dev Neurobiol 67: 1348-1361, 2007.
44. Golding SE, Morgan RN, Adams BR, Hawkins AJ, Povirk LF and Valerie K: Pro-survival AKT and ERK signaling from EGFR and mutant EGFRvIII enhances DNA double-strand break repair in human glioma cells. Cancer Biol Ther 8: 730-738, 2009.

45. Toulany M, Lee KJ, Fattah KR, Lin YF, Fehrenbacher B, Schaller M, Chen BP, Chen DJ and Rodemann HP: Akt promotes post-irradiation survival of human tumor cells through initiation, progression, and termination of DNA-PKcs-dependent DNA double-strand break repair. Mol Cancer Res 10: 945-957, 2012.

46. Toulany M and Rodemann HP: Phosphatidylinositol 3-kinase/Akt signaling as a key mediator of tumor cell responsiveness to radiation. Semin Cancer Biol 35: 180-190, 2015.

47. Fan QW and Weiss WA: Inhibition of PI3K-Akt-mTOR signaling in glioblastoma by mTORC1/2 inhibitors. Methods Mol Biol 821: 349-359, 2012.

48. Westhoff MA, Karpel-Massler G, Brühl O, Enzenmüller S, La Ferla-Brühl K, Siegelin MD, Nonnenmacher L and Debatin KM: A critical evaluation of PI3K inhibition in Glioblastoma and Neuroblastoma therapy. Mol Cell Ther 2: 32, 2014.

49. Opel D, Westhoff MA, Bender A, Braun V, Debatin KM and Fulda S: Phosphatidylinositol 3-kinase inhibition broadly sensitizes glioblastoma cells to death receptor- and drug-induced apoptosis. Cancer Res 68: 6271-6280, 2008.

50. Trovò L, Ahmed T, Callaerts-Vegh Z, Buzzi A, Bagni C, Chuah M, Vandendriessche T, D'Hooge R, Balschun D and Dotti CG: Low hippocampal $\mathrm{PI}(4,5) \mathrm{P}(2)$ contributes to reduced cognition in old mice as a result of loss of MARCKS. Nat Neurosci 16: 449-455, 2013.

51. Wang J, Gambhir A, Hangyás-Mihályné G, Murray D, Golebiewska U and McLaughlin S: Lateral sequestration of phosphatidylinositol 4,5-bisphosphate by the basic effector domain of myristoylated alanine-rich C kinase substrate is due to nonspecific electrostatic interactions. J Biol Chem 277: 34401-34412, 2002.

52. Glaser M, Wanaski S, Buser CA, Boguslavsky V, Rashidzada W, Morris A, Rebecchi M, Scarlata SF, Runnels LW, Prestwich GD, et al: Myristoylated alanine-rich C kinase substrate (MARCKS) produces reversible inhibition of phospholipase $\mathrm{C}$ by sequestering phosphatidylinositol 4,5-bisphosphate in lateral domains. J Biol Chem 271: 26187-26193, 1996.

53. VadlakondaL,Pasupuleti M and Pallu R: Role of PI3K-AKT-mTOR and Wnt Signaling Pathways in Transition of G1-S Phase of Cell Cycle in Cancer Cells. Front Oncol 3: 85, 2013.

54. Jarboe JS, Anderson JC, Duarte CW, Mehta T, Nowsheen S, Hicks PH, Whitley AC, Rohrbach TD, McCubrey RO, Chiu $\mathrm{S}$, et al: MARCKS regulates growth and radiation sensitivity and is a novel prognostic factor for glioma. Clin Cancer Res 18: 3030-3041, 2012.

55. Masaki T, Tokuda M, Yoshida S, Nakai S, Morishita A, Uchida N, Funaki T, Kita Y, Funakoshi F, Nonomura T, et al: Comparison study of the expressions of myristoylated alanine-rich $\mathrm{C}$ kinase substrate in hepatocellular carcinoma, liver cirrhosis, chronic hepatitis, and normal liver. Int J Oncol 26: 661-671, 2005.

56. Chen $\mathrm{CH}$, Statt $\mathrm{S}$, Chiu CL, Thai $\mathrm{P}$, Arif M, Adler KB and Wu R: Targeting myristoylated alanine-rich $C$ kinase substrate phosphorylation site domain in lung cancer. Mechanisms and therapeutic implications. Am J Respir Crit Care Med 190: 1127-1138, 2014.

57. Li H, Chen G, Zhou B and Duan S: Actin filament assembly by myristoylated alanine-rich $\mathrm{C}$ kinase substrate-phosphatidylinositol-4,5-diphosphate signaling is critical for dendrite branching. Mol Biol Cell 19: 4804-4813, 2008.

58. Nairn AC and Aderem A: Calmodulin and protein kinase C cross-talk: The MARCKS protein is an actin filament and plasma membrane cross-linking protein regulated by protein kinase $C$ phosphorylation and by calmodulin. Ciba Found Symp 164: 145-161, 1992.

59. Sundaram M, Cook HW and Byers DM: The MARCKS family of phospholipid binding proteins: Regulation of phospholipase $\mathrm{D}$ and other cellular components. Biochem Cell Biol 82: 191-200, 2004.

60. Adan A, Kiraz Y and Baran Y: Cell proliferation and cytotoxicity sssays. Curr Pharm Biotechnol 17: 1213-1221, 2016.

61. Posimo JM, Unnithan AS, Gleixner AM, Choi HJ, Jiang Y, Pulugulla SH and Leak RK: Viability assays for cells in culture. J Vis Exp 83: 50645, 2014.

62. Yu D, Makkar G, Dong T, Strickland DK, Sarkar R and Monahan TS: MARCKS signaling differentially regulates vascular smooth muscle and endothelial cell proliferation through a KIS-, p27kip1- dependent mechanism. PLoS One 10: e0141397, 2015.

63. Franken NA, Rodermond HM, Stap J, Haveman J and van Bree C: Clonogenic assay of cells in vitro. Nat Protoc 1: 2315-2319, 2006. 
64. Borràs M, Armengol $\mathrm{G}$, De Cabo M, Barquinero JF and Barrios L: Comparison of methods to quantify histone $\mathrm{H} 2 \mathrm{AX}$ phosphorylation and its usefulness for prediction of radiosensitivity. Int J Radiat Biol 91: 915-924, 2015.

65. Thinon E, Serwa RA, Broncel M, Brannigan JA, Brassat U, Wright MH, Heal WP, Wilkinson AJ, Mann DJ and Tate EW: Global profiling of co- and post-translationally N-myristoylated proteomes in human cells. Nat Commun 5: 4919, 2014.

66. Ridley AJ: Rho GTPases and cell migration. J Cell Sci 114: 2713-2722, 2001.

67. Lott $\mathrm{K}$ and Cingolani $\mathrm{G}$ : The importin $\beta$ binding domain as a master regulator of nucleocytoplasmic transport. Biochim Biophys Acta 1813: 1578-1592, 2011.

68. Vargova J, Vargova K, Dusilkova N, Kulvait V,Pospisil V, Zavadil J, Trneny M, Klener P and Stopka T: Differential expression, localization and activity of MARCKS between mantle cell lymphoma and chronic lymphocytic leukemia. Blood Cancer J 6: e475, 2016.

69. Herhaus L, Perez-Oliva AB, Cozza G, Gourlay R, Weidlich S, Campbell DG, Pinna LA and Sapkota GP: Casein kinase 2 (CK2) phosphorylates the deubiquitylase OTUB1 at Ser16 to trigger its nuclear localization. Sci Signal 8: ra35, 2015.

70. Gao Y and Wang HY: Casein kinase 2 Is activated and essential for Wnt/beta-catenin signaling. J Biol Chem 281: 18394-18400, 2006.

71. Tu X, Joeng KS, Nakayama KI, Nakayama K, Rajagopal J, Carroll TJ, McMahon AP and Long F: Noncanonical Wnt signaling through $\mathrm{G}$ protein-linked $\mathrm{PKC}$ delta activation promotes bone formation. Dev Cell 12: 113-127, 2007.

72. Jin BY, Lin AJ, Golan DE and Michel T: MARCKS protein mediates hydrogen peroxide regulation of endothelial permeability. Proc Natl Acad Sci USA 109: 14864-14869, 2012.
73. Chen WC, McBride WH, Iwamoto KS, Barber CL, Wang CC, Oh YT, Liao YP, Hong JH, de Vellis J and Shau H: Induction of radioprotective peroxiredoxin-I by ionizing irradiation. J Neurosci Res 70: 794-798, 2002.

74. Mesiwala AH, Farrell L, Santiago P, Ghatan S and Silbergeld DL: The effects of hydrogen peroxide on brain and brain tumors. Surg Neurol 59: 398-407, 2003.

75. Xu XH, Deng CY, Liu Y, He M, Peng J, Wang T, Yuan L, Zheng ZS, Blackshear PJ and Luo ZG: MARCKS regulates membrane targeting of Rab10 vesicles to promote axon development. Cell Res 24: 576-594, 2014.

76. Yu D, Makkar G, Strickland DK, Blanpied TA, Stumpo DJ, Blackshear PJ, Sarkar R and Monahan TS: Myristoylated alanine-rich protein kinase substrate (MARCKS) regulates small GTPase Racl and Cdc42 activity and is a critical mediator of vascular smooth muscle cell migration inintimal hyperplasia formation. J Am Heart Assoc 4: e002255, 2015.

77. Patel AP, Tirosh I, Trombetta JJ, Shalek AK, Gillespie SM, Wakimoto H, Cahill DP, Nahed BV, Curry WT, Martuza RL, et al: Single-cell RNA-seq highlights intratumoral heterogeneity in primary glioblastoma. Science 344: 1396-1401, 2014.

This work is licensed under a Creative Commons Attribution-NonCommercial-NoDerivatives 4.0 International (CC BY-NC-ND 4.0) License. 